OPEN ACCESS

Edited by:

Lei Chen,

Tianjin University, China

Reviewed by:

Jun-chang Guan,

Bengbu Medical College, China

Haiyang Xia,

Taizhou University, China

Samir Jaoua,

Qatar University, Qatar

${ }^{*}$ Correspondence:

José E. Barboza-Corona

josebar@ugto.mx

Specialty section:

This article was submitted to Microbiotechnology, Ecotoxicology and Bioremediation,

a section of the journal

Frontiers in Microbiology

Received: 19 September 2019 Accepted: 17 December 2019

Published: 14 January 2020

Citation:

Martínez-Zavala SA,

Barboza-Pérez UE,

Hernández-Guzmán G, Bideshi DK and Barboza-Corona JE (2020)

Chitinases of Bacillus thuringiensis: Phylogeny, Modular Structure,

and Applied Potentials.

Front. Microbiol. 10:3032. doi: 10.3389/fmicb.2019.03032

\section{Chitinases of Bacillus thuringiensis: Phylogeny, Modular Structure, and Applied Potentials}

\author{
Sheila A. Martínez-Zavala' ${ }^{1}$ Uriel E. Barboza-Pérez², Gustavo Hernández-Guzmán ${ }^{1,3}$, \\ Dennis K. Bideshi',5 and José E. Barboza-Corona ${ }^{1,3 *}$ \\ ${ }^{1}$ Graduate Program in Biosciences, Life Science Division, University of Guanajuato Campus Irapuato-Salamanca, \\ Guanajuato, Mexico, ${ }^{2}$ School of Biological Sciences, The University of Edinburgh, Edinburgh, United Kingdom, ${ }^{3}$ Department \\ of Biological Sciences, California Baptist University, Riverside, CA, United States, ${ }^{4}$ Department of Entomology, University \\ of California, Riverside, Riverside, CA, United States, ${ }^{5}$ Food Department, Life Science Division, University of Guanajuato \\ Campus Irapuato-Salamanca, Guanajuato, Mexico
}

The most important bioinsecticide used worldwide is Bacillus thuringiensis and its hallmark is a rich variety of insecticidal Cry protein, many of which have been genetically engineered for expression in transgenic crops. Over the past 20 years, the discovery of other insecticidal proteins and metabolites synthesized by $B$. thuringiensis, including chitinases, antimicrobial peptides, vegetative insecticidal proteins (VIP), and siderophores, has expanded the applied value of this bacterium for use as an antibacterial, fungicidal, and nematicidal resource. These properties allow us to view $B$. thuringiensis not only as an entity for the production of a particular metabolite, but also as a multifaceted microbial factory. In particular, chitinases of $B$. thuringiensis are secreted enzymes that hydrolyze chitin, an abundant molecule in the biosphere, second only to cellulose. The observation that chitinases increase the insecticidal activity of Cry proteins has stimulated further study of these enzymes produced by $B$. thuringiensis. Here, we provide a review of a subset of our knowledge of $B$. thuringiensis chitinases as it relates to their phylogenetic relationships, regulation of expression, biotechnological potential for controlling entomopathogens, fungi, and nematodes, and their use in generating chitin-derived oligosaccharides (ChOGs) that possess antibacterial activities against a number of clinically significant bacterial pathogens. Recent advances in the structural organization of these enzymes are also discussed, as are our perspective for future studies.

Keywords: Bacillus thuringiensis, chitinases, domains analysis, regulation, phylogeny, insecticidal activity, antifungal, nematocidal

\section{INTRODUCTION}

The sporogenic Gram-positive bacterium Bacillus thuringiensis has gained preeminence among microbial bioinsecticides, including those based on formulations of entomopathogenic fungi, viruses, nematodes, and other bacteria, owing to its insecticidal properties and commercial success worldwide ( 211,000,000 USD; Lacey et al., 2015). The insecticidal activities of B. thuringiensis are generally target-specific and result from proteinaceous protoxins (Cry, crystal; Cyt, cytolytic; 
$\delta$-endotoxins) that are synthesized at high levels and then crystallized during the sporulation phase of growth (Figure 1). These crystalline inclusions (Cry crystals), also called parasporal bodies, are easily observed with phase contrast microscopy. Cry crystals represent the hallmark of $B$. thuringiensis and its presence distinguishes it from other Bacillus species, including $B$. cereus, $B$. anthracis, and B. subtilis. When Cry crystals are ingested, they dissolve in the midgut of susceptible larvae. Subsequently, solubilized Cry protoxins are proteolytically activated by enzymes in the digestive juice to generate active entomotoxins that bind to various receptors in the midgut, a precursor to destabilization of osmotic balance and degradation of the midgut epithelia and larval mortality. Indeed, larvae of a number of agronomical pests (e.g., Plutella xylostella, Spodoptera frugiperda) and arthropod vectors of human diseases (e.g., Culex, Aedes, and Anopheles species) are susceptible to these toxins. Moreover, a wide variety of cry genes have been cloned and modified for expression in transgenic plants to resist attack and infestation by insects (Palma et al., 2014). Most studies on B. thuringiensis have focused on molecular characterization of Cry proteins, mechanisms of toxicity, crystal structure, and identification of new strains that have commercial potential. In contrast, significantly less attention has been paid to other biomolecules of applied interest. Nevertheless, there is growing interest in less-known metabolites synthesized by $B$. thuringiensis, including chitinases (Chi), bacteriocins, vegetative insecticidal proteins (VIP), and siderophores, as they have potential applied value not only in insect control, but also as antibacterial, fungicidal, nematicidal and acaricidal agents, and their ability to directly or indirectly promote plant growth (Lee et al., 2009; De la Fuente-Salcido et al., 2013; Casados-Vázquez et al., 2017, 2018; Jouzani et al., 2017; Azizoglu, 2019). In addition, B. thuringiensis also synthesizes proteins called parasporins that lack insecticidal activity, but which are active against human cancer cells (Ohba et al., 2009). Interestingly, it was recently reported that Cry1 Ab and Cry1Ac are also cytotoxic to cervical cancer (HeLa) cells (Mendoza-Almanza et al., 2019).

Chitin is a polymer composed of repeating units of $N$-acetyl$D$-glucosamine and it is found in insects, fungi, shrimp shells, fish scales, mollusks, and also in bird plumage and butterfly wings (Morganti, 2012). It is the second most abundant biopolymer in nature, surpassed only by cellulose. Chitosan is a deacetylated chitin derivate with antibacterial activities. It is commonly used in the manufacture of cosmetics, wood dressings, pool-water treatment agents, and edible films. The use of chitin/chitosan present in seafood shells has also been proposed as a viable alternative to plastics which when used indiscriminately present a major environmental hazard (Drahl, 2019). Chitin occurs as highly ordered, crystalline microfibrils, forming three polymorphs $(\alpha, \beta$ and $\gamma)$ composed of $\sim 100$ to 8000 GlcNAc residues depending on the chitin source (Kaya et al., 2017). The $\alpha$-type is the most stable form. It possesses strong intermolecular bonding and is found in shells of crustaceans, fungi cell walls, and in insect cuticles. $\beta$-chitin has weak intermolecular interactions, and it has been observed in association with proteins in squid pens, cell walls of diatoms, and in the lorica built by seaweeds or protozoa. $\gamma$-chitin is considered to be a combination of $\alpha$ - and $\beta$-chitin, and it has been detected in Ptinus beetle cocoon fibers, the cocoon of Orgyia dubia, and the stomach of Loligo sp. (squid) (Herth et al., 2011; Kaya et al., 2017).

Biological structures made of chitin are prime targets for chitinolytic enzymes, and as such, phytopathogenic fungi or pest insects are susceptible to degradation by chitinases (Morales de la Vega et al., 2006; Juárez-Hernández et al., 2015; Hollensteiner et al., 2017). Chitinases are produced and secreted by viruses, prokaryotes, and eukaryotes, including humans, plants, fungi, and insects, which interestingly may or not have chitin. Bacteria synthesize a myriad of chitinolytic enzymes to transform chitin to carbon and nitrogen sources which together with other metabolites promote plant growth. Previously, chitinases were classified as endochitinases, exochitinases (chitobiosidases, chitobiases), and $\mathrm{N}$-acetylglucosaminidases, according to the products generated during the hydrolysis process. Currently, and according to the CAZy database ${ }^{1}$, chitinolytic enzymes are classified in two general groups: chitinases (EC 3.2.1.14) and $\beta$-N-acetylhexosaminidases (EC 3.2.1.52), previously called endochitinases and exochitinases, respectively. Chitinases cleave chitin chains at internal sites randomly, whereas $\beta-N$-acetylhexosaminidases hydrolyze chitin from the non-reducing end of the molecule by removing GlcNAc residues. These enzymes are further grouped into different glycoside hydrolases $(\mathrm{GH})$ families based on their amino acid sequence similarities: endochitinases represent four groups (GH18, GH19, GH23, and GH48), whereas $\beta-N$ acetylhexosaminidases represent six groups (GH3, GH5, GH18, GH20, GH84, GH116). Most bacterial chitinases belong to the GH18 family.

In particular, interest in the applied value of $B$. thuringiensis chitinases (Bt Chi) was initiated in the 1970s when it was demonstrated that enzymes secreted by this bacterium hydrolyzed chitin (Chigalelchik, 1976). Later, it was shown that $B$. thuringiensis produces chitinases that when used in combination with other components, including Cry proteins, contributed to its virulence (Smirnoff, 1974; Regev et al., 1996; Guttmann and Ellar, 2000). Soon thereafter, cloning of genes coding for $B$. thuringiensis chitinases was reported (Thamthiankul et al., 2001; Barboza-Corona et al., 2003) which initiated the development of recombinant $B$. thuringiensis strains expressing homologous chitinases. More recently, elucidation of the three-dimensional structure of chitinase ChiA74 (JuárezHernández et al., 2019) laid a foundation for performing directed evolutionary studies to create a cassette of more stable and efficient enzymes for practical purposes. Several excellent reviews have been published on Cry proteins and a few other metabolites of B. thuringiensis (De la Fuente-Salcido et al., 2013; Palma et al., 2014; Jouzani et al., 2017; Azizoglu, 2019), but not on chitinases produced by this bacterium. In this review, our objective is to survey pertinent information published on chitinases of $B$. thuringiensis, with a focus on their phylogeny, regulation, and potential to control insects, microorganisms

\footnotetext{
${ }^{1}$ http://www.cazy.org/Glycoside-Hydrolases.html
} 


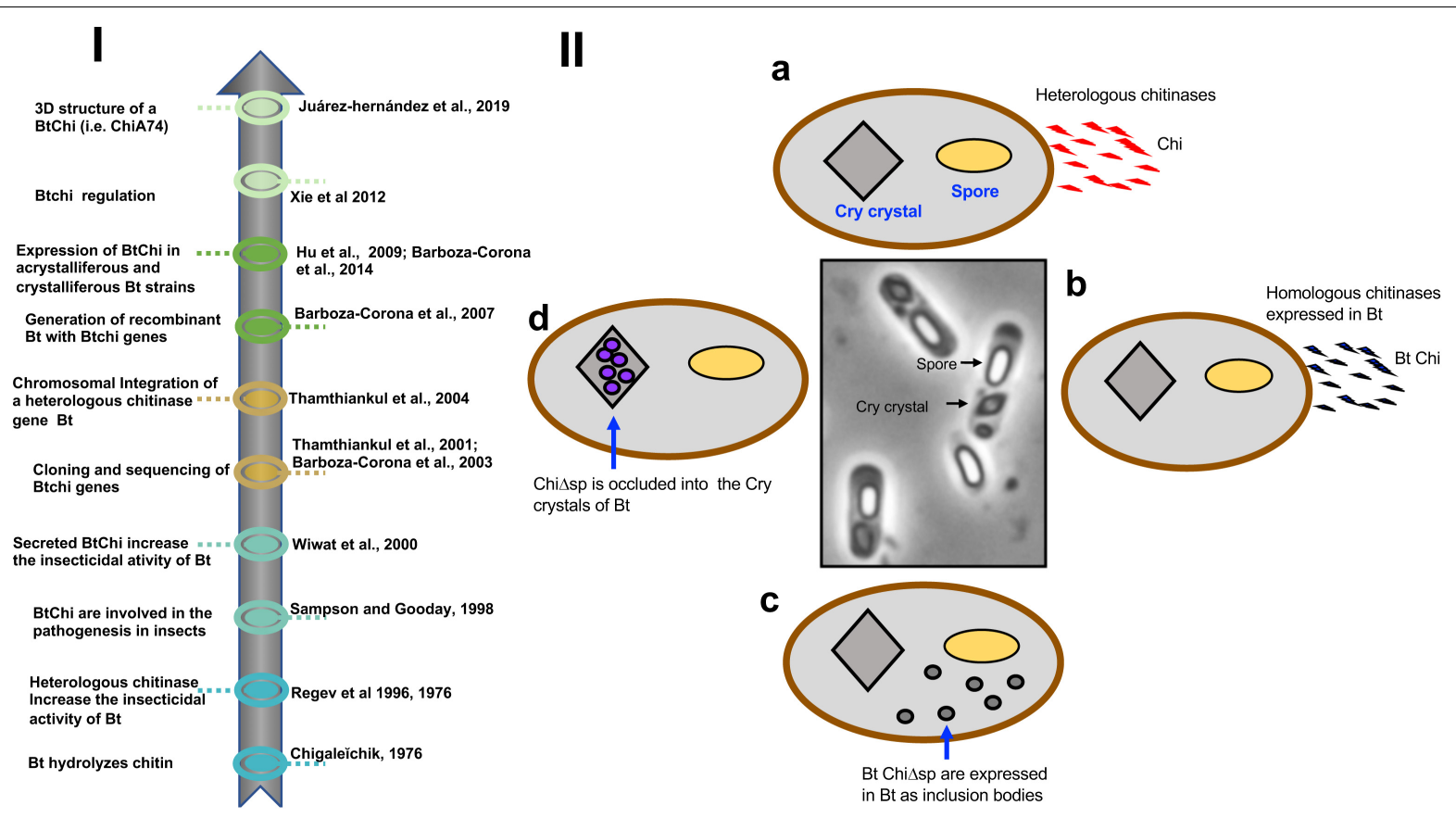

FIGURE 1 | (I) Timeline. A brief history of the use of homologous and heterologous chitinases to increase the insecticidal activity of B. thuringiensis. (II) Different options for the development of recombinant strains of $B$. thuringiensis expressing chitinases. (a) The bacterium can be transformed with heterologous chitinase genes obtained from bacteria other than $B$. thuringiensis. Chitinases harbor signal peptides and are secreted from the cells. (b) The bacterium can be transformed with homologous chitinase genes obtained from different strains of $B$. thuringiensis. Chitinases harbor signal peptides and are secreted from the cells. (c) Chitinase genes from $B$. thuringiensis are engineered and the signal peptide is deleted. Chitinases are expressed inside the cells as inclusion bodies along with the spores and insecticidal Cry proteins. (d) Chitinase genes lacking signal peptides are transcriptionally fused to the C-terminal encoding moiety of cry 1 genes, facilitating the formation of disulfide bridges between the chimeric construct and Cry proteins. This strategy putatively allows the formation of chimeric crystals made of Cry and chitinases. Bt, B. thuringiensis; Chi, chitinases; Bt Chi, chitinases from Bt, Cry crystals, parasporal bodies made of Cry proteins; Chi $\Delta \mathrm{sp}$, chitinase lacking signal peptide; Bt Chi $\Delta$ sp, chitinase from Bt lacking a signal peptide.

and nematodes. Recent advances in the structural organization of these enzymes are also discussed, as are our perspective for future studies.

\section{CHITINASES OF B. thuringiensis AND ITS MODULAR ORGANIZATION}

Chitinases produced by $B$. thuringiensis may play different roles that contribute to the survival of this bacterium under different conditions. For example, these enzymes can be used (i) to sequester and assimilate chitin and use it as a sole source of carbon, and (ii) to act as a virulence factor that promotes the establishment of successful infection by $B$. thuringiensis by compromising structural components, such as the peritrophic membrane through which activated Cry proteins transit in the target host. (iii) Additionally, it is well established that B. thuringiensis propagate in moribund and deceased larvae following infection and that several bacterial-based enzymes including proteases, lipases, esterases, and chitinases amplify this process. Chitinases, in particular, can participates in the destruction of the cuticle thereby facilitating the release and dissemination of toxins and spores, and establishment of the bacterium in other ecological niches (e.g., soil, phylloplane) (Argola-Filho and Loguercio, 2014; Malovichko et al., 2019).
Chitinases of $B$. thuringiensis are synthesized at a basal level under the regulation of native promoters, and increased yields require the addition of chitin to the culture medium. To significantly increase chitinase yield for applied commercial purposes, it is essential to identify a myriad of chitinase genes from different niches together with the physical and biochemical parameters that affect the activity of their corresponding enzyme, and also to select the best candidates for hyperexpression in recombinant strains of $B$. thuringiensis. To date, more than 1000 complete genomes and whole-genome shotgun sequences of $B$. thuringiensis have been deposited in the National Center for Biotechnology Information ${ }^{2}$. However, $\sim 50$ chitinase genes harbored in different subspecies of this bacterium have been reported in GenBank. Most of the chitinase genes were cloned and sequenced in China ( $\sim 1 \%)$, followed by Mexico and Pakistan $(\sim 17$ and $15 \%$, respectively), and $\sim 2-4 \%$ from Thailand, Brazil, Tunisia, Turkey, Vietnam, Japan, Korea, Egypt, and India (Table 1). Based on amino acid sequence alignments, Barboza-Corona et al. (2008) classified chitinases of B. thuringiensis in four groups. Most of these chitinases showed identities from $\sim 90$ to $99 \%$, but the main difference was observed in the C-terminal end of the deduced amino acid sequences. For example, Group 3 differs from groups 2 and 1 because its

\footnotetext{
2www.ncbi.nlm.nih.gov/
} 
TABLE 1 | Chitinase genes of Bacillus thuringiensis reported in the GenBank.

\begin{tabular}{|c|c|c|c|c|c|}
\hline Number & Accession numbers & Subspecies of $B$. thuringiensis & Reporting year in the GenBank & Origin country & References*** \\
\hline 1 & BTU89796 & pakistani & 1997 & Thailand & Thamthiankul et al., 2001 \\
\hline 2 & AF424979 & kenyae & 2003 & México & Barboza-Corona et al., 2003 \\
\hline 3 & AF526379 & israelensis, & 2003 & China & Zhong et al., 2003 \\
\hline 4 & AY456381 & entomocidus & 2003 & China & Unpublished \\
\hline 5 & AY452507 & alesti & 2003 & China & Lin and Xiong, 2004 \\
\hline 6 & AY455290 & canadensis, strain HD224 & 2003 & China & Unpublished \\
\hline 7 & EF211999 & Nti**, strain BT-7216 & 2004 & China & Unpublished \\
\hline 8 & AY452506 & toumanoffi & 2004 & China & Unpublished \\
\hline 9 & AY279975 & aizawai & 2004 & Thailand & Unpublished \\
\hline 10 & AJ635226 & kurstaki & 2005 & Tunisia & Driss et al., 2005 \\
\hline 11 & AY074882 & $\mathrm{Nti}$ & 2005 & China & Unpublished \\
\hline 12 & DQ512474 & colmeri strain 15A3 & 2006 & China & Unpublished \\
\hline 13 & DQ993175 & morrisoni & 2006 & Turkey & Unpublished \\
\hline 14 & AY129671 & sotto & 2006 & China & Unpublished \\
\hline 15 & EF427670 & $\mathrm{Nti}$ & 2007 & China & Unpublished \\
\hline 16 & EU030625 & Nti & 2007 & China & Unpublished \\
\hline 17 & EF581163 & kurstaki, strain HD-73 & 2008 & México & Barboza-Corona et al., 2008 \\
\hline 18 & EU557354 & Nti, strain KR 19-22 & 2008 & Korea & Unpublished \\
\hline 19 & EU373094 & Nti, strain 97243-1 & 2008 & China & Unpublished \\
\hline 20 & EU373095 & Nti, strain $\mathrm{H} 14$ & 2009 & China & Unpublished \\
\hline 21 & GQ183830 & konkukian strain S4 & 2009 & Pakistan & Unpublished \\
\hline 22 & GQ183831 & konkukian strain S4 & 2011 & Pakistan & Unpublished \\
\hline 23 & JX474751 & israelensis, NRRL HD-522 & 2012 & Egypt & Unpublished \\
\hline 24 & HQ418219 & Nti, strain RN52 & 2013 & México & Rosas-García et al., 2013 \\
\hline 25 & HQ418218 & Nti, strain MR33 & 2013 & México & Rosas-García et al., 2013 \\
\hline 26 & HQ418217 & Nti, strain MR21 & 2013 & México & Rosas-García et al., 2013 \\
\hline 27 & HQ418216 & Nti, strain MR11 & 2013 & México & Rosas-García et al., 2013 \\
\hline 28 & HQ418215 & Nti, strain MR10 & 2013 & México & Rosas-García et al., 2013 \\
\hline 29 & HE993892 & Nti, strain SBS-BT5 & 2013 & Pakistan & Unpublished \\
\hline 30 & KJ010822 & Nti, strain HTS-S-38 & 2014 & China & Unpublished \\
\hline 31 & KJ508093 & Nti, strain DLD171 & 2014 & China & Unpublished \\
\hline 32 & HF542112* & Nti, strain BUPM173 & 2014 & Tunisia & Unpublished \\
\hline 33 & HF542113* & Nti, strain BUPM85 & 2014 & Tunisia & Unpublished \\
\hline 34 & HG792452 & Nti, strain SBS-BT6 & 2014 & Pakistan & Unpublished \\
\hline 35 & HG792451 & Nti, strain SBS-BT3 & 2014 & Pakistan & Unpublished \\
\hline 36 & HG792449 & Nti, strain SBS-BT5 & 2014 & Pakistan & Unpublished \\
\hline 37 & KM249886* & Nti, strain BC-7 & 2014 & India & Unpublished \\
\hline 38 & KF671757 & tenebrionis, strain 9602 & 2015 & China & Ni et al., 2015 \\
\hline 39 & KJ764712 & tenebrionis, DSM2803 & 2015 & México & De la Fuente-Salcido et al., 2016 \\
\hline 40 & KJ676691 & Nti, strain 1555 & 2015 & Brazil & Unpublished \\
\hline 41 & EF103273 & colmeri 15A3 & 2015 & China & Chen et al., 2007 \\
\hline 42 & HE995800 & Nti, strain SBS-Bt5 & 2015 & Pakistan & Unpublished \\
\hline 43 & EU734811* & Nti, isolate 66 & 2016 & Egypt & Unpublished \\
\hline 44 & GQ899142* & kurstaki & 2016 & India & Unpublished \\
\hline 45 & LC194873 & israelensis ATCC 35646 & 2017 & Japan & Honda et al., 2017 \\
\hline 46 & MF630994 & kurstaki strain MSS1.1 & 2017 & Viet Nam & Unpublished \\
\hline 47 & EF197878 & $\mathrm{Nti}$ & 2018 & China & Unpublished \\
\hline 48 & MK313782 & Nti, strain HS66 & 2019 & China & Unpublished \\
\hline 49 & MK032857 & Nti, strain HD-73 & 2019 & China & Unpublished \\
\hline
\end{tabular}

*Partial sequences. **Nti: Not indicated. ***Information according with the GenBank data (www.ncbi.nlm.nih.gov).

members have an addition of $\sim 12$ or 24 amino acids, respectively. ChiA71, a chitinase from B. thuringiensis subsp. pakistani Group 1 includes chitinase ChiA74 from B. thuringiensis subsp. (Thamthiankul et al., 2001). ChiA74 and ChiA71 were the first kenyae (Barboza-Corona et al., 2003), whereas four contains only two chitinases from B. thuringiensis genes that were cloned, 
sequenced and characterized. Interestingly, the main difference between ChiA74 (Group 1) and ChiA71 (Group 4), was the presence of 118 amino acids in the former, but absent in the latter. Also, a 93-amino acid sequence present in the C-terminal region of ChiA71 is absent in ChiA74 (Barboza-Corona et al., 2008). As bacterial chitinases are secreted enzymes they also contain a signal peptide, usually located at the $\mathrm{N}$-terminus, to initiate translocation of the enzyme through the cell wall architecture to the external environment ( $\mathrm{Li}$ and $\mathrm{Li}, 2009$ ). Interesting, the signal peptide of chitinase of $B$. thuringiensis is also recognized by the secretion machinery of E. coli, a Gram-negative bacterium (Barboza-Corona et al., 2003; De la Fuente-Salcido et al., 2016). Most of the chitinases of $B$. thuringiensis have a molecular mass of $\sim 70 \mathrm{kDa}$ (Thamthiankul et al., 2001; Barboza-Corona et al., 2003, 2008; Zhong et al., 2003; Lin and Xiong, 2004; Driss et al., 2005; De la Fuente-Salcido et al., 2016; Honda et al., 2017), although chitinases of $\sim 30 \mathrm{kDa}$ have been reported (Arora et al., 2003; Chen et al., 2007); in general, they have optimal $\mathrm{pH}$ activity around 6.5-8.5 with a range temperature of 50$60^{\circ} \mathrm{C}$. It is difficult to compare the activity of chitinases from B. thuringiensis with other bacterial chitinases, mainly because the differences in the substrates used for the assays and the way to express the units of chitinase activity, i.e., there is no a standardized protocol for determining the activity of bacterial chitinases. Nevertheless, using $4 \mathrm{MU}-(\mathrm{GlcNAc})_{3}$ as substrate, it has been observed that ChiA74 from thuringiensis has a catalytic efficiency of $1.77 \mathrm{~s}^{-1} \mu \mathrm{M}^{-1}$ which is higher than ChiA1 from B. circulans $\left(0.4 \mathrm{~s}^{-1} \mu \mathrm{M}^{-1}\right)$, but lower than ChiA and ChiB from Serratia marcescens with values of 16 and $8.4 \mathrm{~s}^{-1} \mu \mathrm{M}^{-1}$, respectively (Watanabe et al., 1993; Casados-Vazquez et al., 2015; Oyeleye and Normi, 2018).

Bacterial chitinases have a modular organization where the catalytic domain can be associated with the following modules: chitinase insertion domain (CID), fibronectin type III-like (FnIII), and chitinase binding domain (CBD) (JuárezHernández et al., 2017, 2019). The modular organization can vary, as evidenced by in silico comparisons with chitinases from other bacteria using the Interpro webserver ${ }^{3}$. ChiA74 from $B$. thuringiensis has a similar organization with a chitinase from B. cereus but differs from other bacterial chitinases (Figure 2). The variation in the modular organization is in agreement with the diversity in chitin substrate structures (Svitil and Kirchman, 1998). Family 18 chitinases composed of enzymes synthesized by Bacillus species are divided into subfamilies $\mathrm{A}$ and $\mathrm{B}$. These subfamilies differ by the presence of a chitin insertion domain (CID) found in subfamily $\mathrm{A}$, but absent in $\mathrm{B}$. The catalytic domain is composed of a TIM-barrel that contains an $(\alpha / \beta) 8$ barrel fold found in many different enzymes. This catalytic domain occasionally has a second domain inserted into the active site of the TIM domain, i.e., CID, which participates in binding and catalytic processes ( $\mathrm{Li}$ and Greene, 2010). $B$. thuringiensis chitinases belong to subfamily A and contain the CID domain (Juárez-Hernández et al., 2019). The CID is composed of five or six anti-parallel $\beta$-strand and one $\alpha$-helix that alongside the TIM barrel substrate-binding cleft forms

${ }^{3}$ www.ebi.ac.uk/interpro/beta/ a wall that increases the depth of the cleft which suggests the CID facilitates orienting and binding longer saccharide substrates (Van Aalten et al., 2000). Most chitinases have one or more chitin-binding domains (CBDs) that are important for interacting with insoluble chitin, and also for facilitating microbial attachment to chitin for subsequent degradation ( Wu et al., 2001; Arora et al., 2013; Lobo et al., 2013). The CBDs belong to different types of Carbohydrate-Binding Modules (CBMs) and the location of CBDs in chitinases is variable. For example, chitinase ChiA74 from B. thuringiensis has one CBD at the C-terminus (Juárez-Hernández et al., 2017), the chitinase from Chitinolyticbacter meiyuanensis (CmChi1) has two CBDs between the signal peptide and the catalytic domain (Zhang et al., 2018), and chitinase Chi92 from A. hydrophila (AhChi92) contains three repeat CBD domains at the C-terminus (Wu et al., 2001). There is evidence to suggest that the CBD affects how the enzyme accesses glycosidic bonds within chitin strands (Svitil and Kirchman, 1998). Aromatic amino acids (W, Y) in the CBD are highly conserved and appear to be essential for hydrophobic binding with the pyranosyl rings of $\mathrm{N}$-acetylglucosamine residues in chitin (Zhong et al., 2015). In particular for ChiA74 the CBD belongs to the carbohydratebinding type 2 domain subfamily $b$ (CBM2b). This domain has a conserved region of $\sim 100$ amino acids uncommon in chitinases, but present in xylanases (Wertz et al., 2017). The fibronectin type III-like domain (FnIII) and surface layer homology domains (SLH domain) are present in chitinases of the genera Bacillus. In particular, $B$. thuringiensis chitinases possess a FnIII domain composed of a $\beta$-sandwich with approximately 100 amino acids. This domain was originally identified in the eukaryotic plasma protein fibronectin and it is part of one of three types of internal repeats (FnI-FnII-FnIII) that arrange other domains in space, acting as a structural spacer (Valk et al., 2017). In bacteria, $\sim 19 \%$ of the FnIII domains are found in proteins directly related to carbohydrate metabolism and proteins that contain carbohydrate-binding domains, such as chitinases and cellulases; the location of this domain is between other domains. According to recent reports, in carbohydrate hydrolyzing enzymes the FnIII domain act as a stable linker in multi-domain proteins, as a carbohydrate surface disruption domain, or as a carbohydrate-binding domain. Watanabe et al. (1994) suggested that FnIII may help maintain the optimal distance and orientation between catalytic and CBDs in BcChiA1. Also, in ChiA74 the FnIII might act as a stable linker between the catalytic regions (CDs) and the CBD (Juárez-Hernández et al., 2019). On the other hand, it has been suggested that the FnIII domain of a chitinase from $B$. thuringiensis subsp. tenebrionis might act synergistically with chitin-binding proteins, helping to attach chitin to the enzyme for efficient substrate hydrolysis (De la Fuente-Salcido et al., 2016).

Finally, the first three-dimensional (3D) structure of the chitinase ChiA74 was elucidated. This crystal structure confirmed the multi-domain assembly of ChiA74 is formed by (i) a CD, (ii) a CID, (iii) a FnIII, and (iv) a chitin binding domain (CBD) (Juárez-Hernández et al., 2019). Moreover, this study demonstrated the importance of the catalytic E211 in the $\mathrm{CD}$, as mutants were inactive against a variety of 


\section{I}

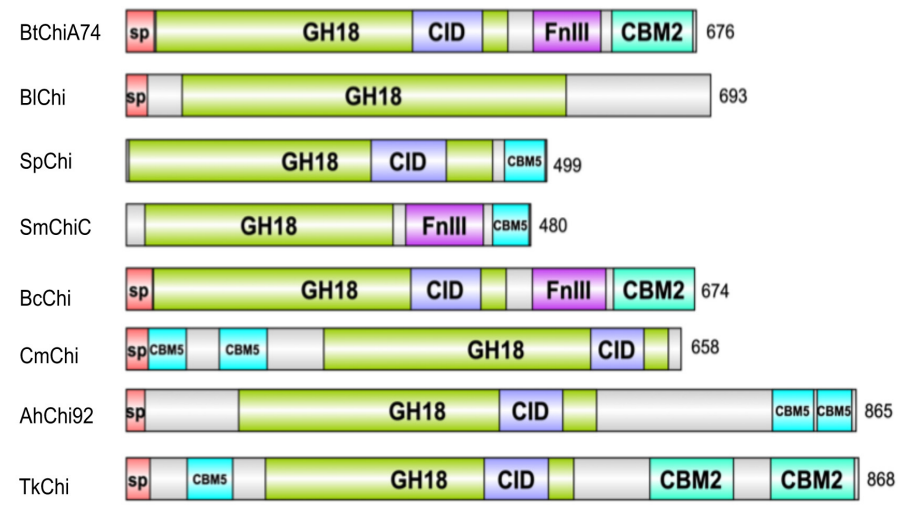

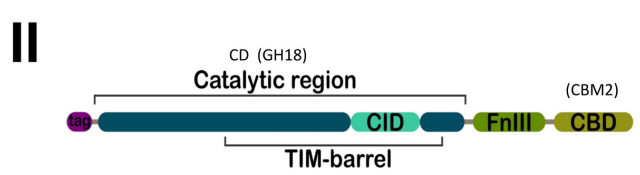

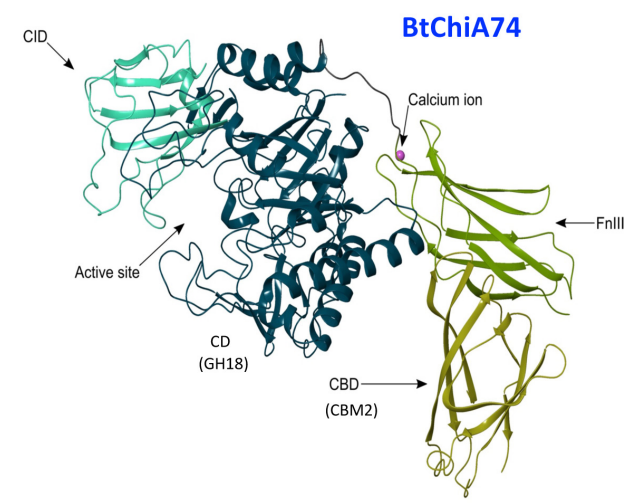

FIGURE 2 | Comparison of the modular structure of chitinases of $B$. thuringiensis with different bacterial chitinases and the three-dimensional structure of the ChiA74 from B. thuringiensis. (I) Modular alignment between different bacterial chitinases. Protein sequences were analyzed using the Interpro webserver (www.ebi.ac.uk/interpro/beta) and the figure was built with the program DOG 1.0 (Ren et al., 2009). The nomenclature used in the CAZy database was maintained. Signal peptide, sp; catalytic domains, GH18; CID, chitinase insertion domain; carbohydrate-binding module, CBM; fibronectin type III domain, Fnlll. Chitinase (Chi) of: Bt, B. thuringiensis (accession number AF424979.1); BI, B. licheniformis (QAS14701.1); Sp, Serratia proteamaculans (AGF70636.1); Sm, S. marcescens (ABI79318.1); Sm, S. marcescens AHH32576.1; BC, B. cereus (FRI-35 AFQ09088.1); Cm, Chitinolyticbacter meiyuanensis (ATN39892.1); Ah, Aeromonas hydrophila (AAG09437.1); Tk, Thermococcus kodakarensis (BAA88380). (II) Crystal structure of the chitinase ChiA74 of $B$. thuringiensis with little additions in the nomenclature to match with (I). The catalytic region (CD) corresponds to the GH18, and chitin binding domain (CBD) to the CBM2 showed in panel (I). This clarification is also shown in (II). The three-dimensional structure was first reported by our group in Juárez-Hernández et al. (2019), Scientific Reports, available online at https://doi.org/10.1038/s41598-019-39464-z.

substrates, including colloidal/crystalline chitins, chitosan, and synthetic fluorogenic compounds, and also suggested that the CBD might play a significant role in the hydrolysis of crystalline chitin.

\section{PHYLOGENETIC ANALYSIS AND CHITINASE EXPRESSION}

To determine the genetic relationships of $B$. thuringiensis chitinases, information of the coding sequences reported to date in the GenBank nucleotide sequence database of the National Center for Biotechnology Information ${ }^{4}$ were used (see also Table 1). Deduced amino acid sequences were aligned with MUSCLE (MUltiple Sequence Comparison by LogExpectation $^{5}$ ). The chitinase from B. cytotoxicus [NC_009674; Bazinet (2017)] was used as an outgroup and the resulting alignment was exported as a Pearson/FastA file and then submitted to Findmodel software ${ }^{6}$ to assess which phylogenetic model optimally described the data. Phylogenetic trees were obtained with MEGA X (Kumar et al., 2018) and constructed using the Maximum Likelihood method and General Time Reversible $+\mathrm{G}$ model. The tree (Figure 3) with the highest log likelihood was obtained with 1000 bootstrap replicates

\footnotetext{
${ }^{4}$ https://www.ncbi.nlm.nih.gov/

${ }^{5}$ https://www.ebi.ac.uk/Tools/msa/muscle/

${ }^{6} \mathrm{https} / /$ www.hiv.lanl.gov/content/sequence/findmodel/findmodel.html
}

(Felsenstein, 1985). The phylogram shows an unrooted topology containing some branches with low bootstrap values, supporting a complex evolutionary history for $B$. thuringiensis chitinases. Most sequences with a small number of amino acid replacements were groups in two sister branches with some polytomy with unresolved nodes. A branch sister of B. cytotoxicus grouped all $B$. thuringiensis chitinases. The most populated branch separates two sisters, grouping two $B$. thuringiensis subsp. pakistani sequences in a branch with $100 \%$ bootstrap, and a branch containing six sister groups, one of them showing the largest number of replacements, and the remaining five sisters showing a small number of replacements per site. Sisters with large amino acid replacements branched in two groups, one composed of five chitinases from B. thuringiensis subsp. pakistani, colmeri, israelensis, and konkukian and second with a single chitinase from B. thuringiensis subsp. aizawai.

Regarding target-specific groupings of chitinases, there is scarce information about the effect of chitinases and associated toxicity to " $n$ " specific hosts. For example, a chitinase from B. thuringiensis subsp. pakistani (GenBank accession number BTU89796) was used to increase the activity of Cry proteins against Aedes aegypti (Thamthiankul et al., 2001), and ChiA74 from B. thuringiensis subsp. kenyae (AF424979) against S. frugiperda, M. sexta, P. xylostella (Lepidoptera), and Aedes aegypti (Diptera) (Casique-Arroyo et al., 2007; Barboza-Corona et al., 2014; Juárez-Hernández et al., 2015; González-Ponce et al., 2017). Besides these, chitinases from B. thuringiensis subsp. tenebrionis strain 9602 (KF671757) were active against 


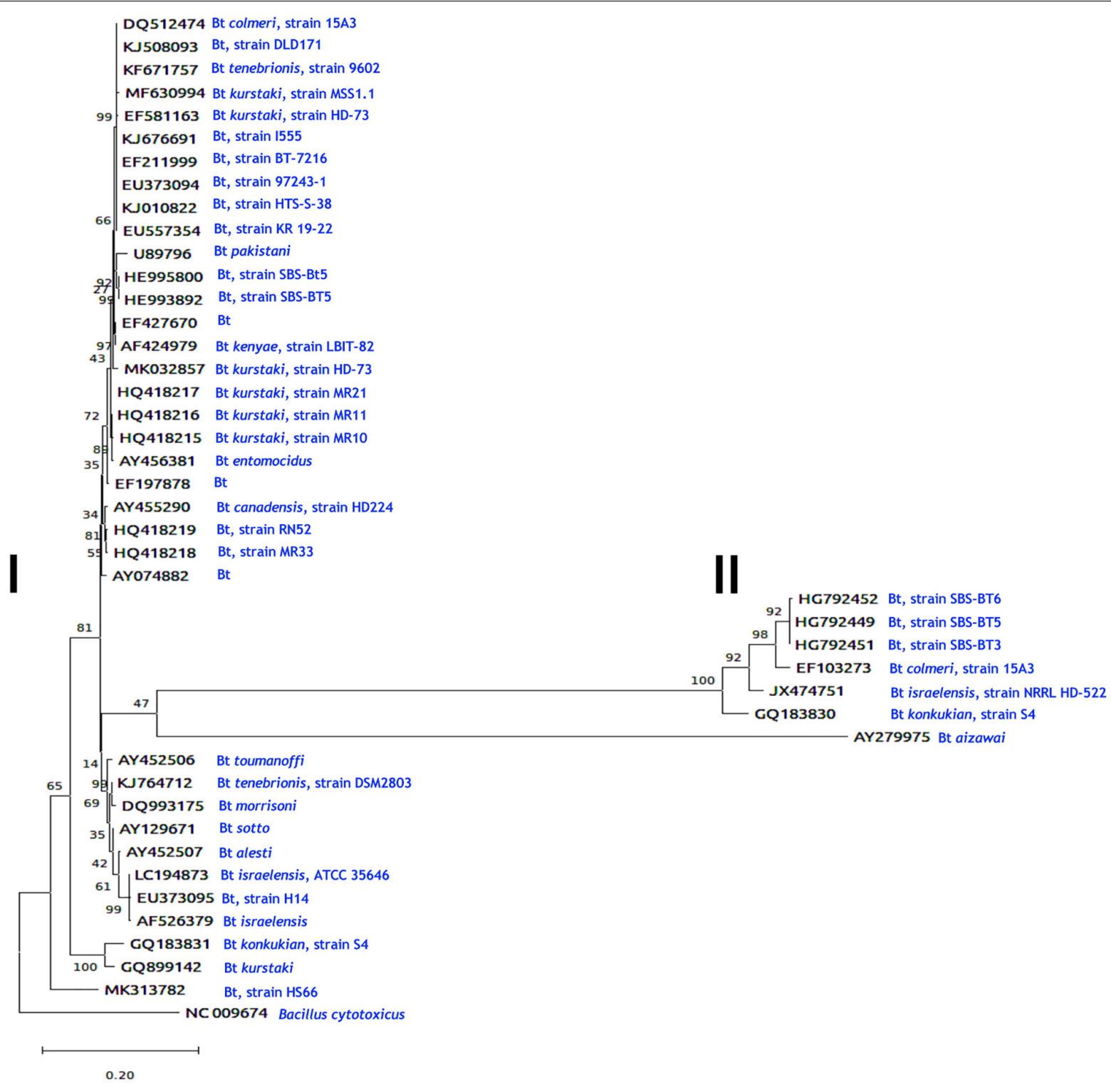

FIGURE 3 | Evolutionary analysis of Bacillus chitinases by the Maximum Likelihood method. The evolutionary history was inferred by using the Maximum Likelihood method and the General Time Reversible model (Nei and Kumar, 2000). The tree with the highest log likelihood (-13605.90) is shown. The percentage of trees in which the associated taxa clustered together is shown next to the branches. Initial tree(s) for the heuristic search were obtained automatically by applying Neighbor-Join and BioNJ algorithms to a matrix of pairwise distances estimated using the Maximum Composite Likelihood (MCL) approach and then selecting the topology with superior log likelihood value. A discrete Gamma distribution was used to model evolutionary rate differences among sites [5 categories (+ $G$, parameter $=1.7979$ ). The tree is drawn to scale, with branch lengths measured in the number of substitutions per site. This analysis involved 44 nucleotide sequences. There was a total of 3234 positions in the final dataset. Evolutionary analyses were conducted in MEGA X (Kumar et al., 2018). To elaborate this figure, information of the coding sequences of Bacillus thuringiensis chitinases reported to date in the GenBank nucleotide sequence database of the National Center for Biotechnology Information (https://www.ncbi.nlm.nih.gov/) were taken. Two main groups were distinguished, (I) and (II). After each accession numbers are indicated the B. thuringiensis (Bt) subspecies and/or the strain types (e.g., Bt colmeri, strain 15A3; Bt, strain DLD171) (see in blue) were chitinases were obtained. B. cytotoxicus was used as an external group. Additional information on the B. thuringiensis strains is shown in Table 1.

Helicoverpa armigera (Lepidoptera) and Caenorhabditis elegans (nematode) (Ni et al., 2015), whereas B. thuringiensis subsp. tenebrionis strain DSM2803 (KJ764712) was active against Colletotrichum gloeosporioides (fungus) (De la Fuente-Salcido et al., 2016). Based on these observations, most chitinases shows high sequence similarity, but at the same time, it is difficult to assign chitinase specificity to a discrete host group of insects. Our resulting phylogram suggests that chitinases from $B$. thuringiensis form two main groups (I and II, Figure 3). In the first group, chitinases from B. thuringiensis subsp. tenebrionis with accession numbers KF671757 and KJ764712 are effective against Helicoverpa armigera, Caenorhabditis elegans, and Colletotrichum 
gloeosporioides, respectively (Ni et al., 2015; De la Fuente-Salcido et al., 2016), but share the same ancestor. Also, B. thuringiensis subsp. pakistani (U89796) and B. thuringiensis subsp. kenyae (AF424979) chitinases that are effective against $A$. aegypti, branch in different groups but share a common ancestor (Thamthiankul et al., 2001; Juárez-Hernández et al., 2015). For the second group, there is no report of the chitinase activity against insects, fungi or nematodes. Because there is scarce evidence about chitinases and their target-specific associations, it is evident that more work is needed to establish the evolutionary histories of $B$. thuringiensis chitinases.

Alternatively, B. thuringiensis chitinase gene promoters (e.g., chiA74 and chiA71) harbor -35 and -10 consensus sequences that show identity with $E$. coli promoters and also with promoters recognized by the housekeeping/early sporulation $\sigma^{\mathrm{A}}$ factor of B. subtilis (Haldenwang, 1995; Thamthiankul et al., 2001; Barboza-Corona et al., 2003; González-Ponce et al., 2019). The fact that chitinase gene promoters from $B$. thuringiensis are recognized by the $E$. coli transcriptional machinery provides an important advantage for heterologous expression because it is relatively much easier to work with $E$. coli than with B. thuringiensis for different reasons. For example, E. coli has a shorter generation time and is a non-sporogenic bacterium. It has been observed that $B$. thuringiensis synthesizes chitinases at basal levels in media lacking chitin, although synthesis can be induced with chitin and repressed with glucose (catabolic repression), factors which may be irrelevant in E. coli. Nevertheless, regardless of whether or not glucose is added to a culture of $B$. thuringiensis, basal chitinase synthesis is not suppressed (Casique-Arroyo et al., 2007; Barboza-Corona et al., 2009; Xie et al., 2010).

The core promoter of the chiA gene of $B$. thuringiensis subsp. israelensis strain 75 (Bti75) was delimited by fusing the $5^{\prime}$ UTR with the $\beta$-galactosidase ( $b g a B)$ gene from $B$. stearothermophilus. When chitin was added to the culture medium, a 2.5-fold increase in the activity of BgaB was observed. Interestingly, a cis-active element of $\sim 16 \mathrm{bp}$, designed dre (DasR responsive elements), is present downstream of the core promoter. The dre element plays a role in gene expression as deletion of this sequence resulted in constitutive expression of the chitinase gene (Xie et al., 2012). The dre sequence has also been reported in other bacteria, including Streptomyces and other Bacillus species (Colson et al., 2007; Bertram et al., 2011). In B. thuringiensis, dre acts as a binding site for a negative transcriptional regulator called YVoABt, an $\mathrm{N}$-acetylglucosamine utilization regulator primarily induced by GlcNAc. YVoABt complexes with the phosphoprotein Hprser $_{45}$-P to bind to dre (Jiang et al., 2015) thereby repressing expression of the chitinase gene. However, when the bacterium utilizes chitin as a substrate, GlcNAc or oligosaccharides derived from chitin are produced which leads to the displacement of the repressor and subsequent gene transcription (Jiang et al., 2015; Cao et al., 2018). The YVoABt regulator is also known as $\mathrm{NagR}_{\mathrm{Bt}}$ because it is an ortholog of NagR in B. subtilis. NagRBt is a pleiotropic transcriptional regulator that upregulates and downregulates at least 27 and 14 genes, respectively, in B. thuringiensis (Cao et al., 2018).

The chitinase gene promoter also contains cre (catabolic response element), which is the binding site of a catabolic control protein A (CcpA) that in different Gram-positive bacteria has been identified as the key regulator of the carbon catabolic repression (CCR) process. CcpA can bind specifically to cre upon binding to phosphoprotein $\mathrm{Hpr}_{-S_{46}}$-P (Deutscher et al., 2006). Deletion of the CcpA regulator increases chitinase gene expression and enzyme activity by $\sim 39$-fold (Jiang et al., 2015). Based on previously reports (Deutscher et al., 2006; Xie et al., 2012; Jiang et al., 2015; Cao et al., 2018), we have depicted a model for the regulation mediated by cre/CcpA and $d r e / \mathrm{NagR}_{\mathrm{B}}$ in Figure 4.

\section{APPLICATION OF CHITINASES}

\section{To Improve the Toxic Activity Against Insects, Phytopathogenic Fungi and Nematodes}

During the 1970s, and 1990s, it was shown that co-application of spore/crystals and heterologous chitinases or spores/crystals and chitinolytic bacteria increased the insecticidal activity of Cry proteins against the spruce budworm (Choristoneura fumiferana) and African cotton leafworm (Spodoptera littoralis) larvae, respectively (Smirnoff, 1974; Regev et al., 1996). The enhanced toxicity of the Cry proteins was apparently due to degradation of the chitin-based peritrophic membrane of larvae which allowed increased access of the toxins to their respective receptors on the midgut cells (Regev et al., 1996). These observations stimulated the use of heterologous chitinases (i.e., chitinases not synthesized by $B$. thuringiensis), such as those synthesized by $S$. marcescens, $B$. circulans, and B. licheniformis, to increase the insecticidal activity of Cry proteins against pest larvae of agricultural importance. For example, $\sim 0.1 \mathrm{mg} / \mathrm{ml}$ chitinase from $S$. marcescens mixed with $\sim 3 \mathrm{mg}$ per $\mathrm{ml}$ of semipurified Cry1C, both produced separately in E. coli, caused a maximal reduction in larval weight compared with the use of $20.0 \mu \mathrm{g}$ of CrylC per $\mathrm{ml}$ without chitinase. Also, the use of a mix of Pseudomonas fluorescens transformed with cry $1 A c 7$ and chi of $S$. marcescens showed enhanced toxicity against the sugarcane borer Eldana saccharina (Downing et al., 2000). As heterologous chitinases mixed with spores/Cry crystals amplified the toxic effect of Cry proteins (Figure 1), the next step was to transform Bt with heterologous genes coding for chitinases. Wiwat et al. (1996) made the first attempt to transform $B$. thuringiensis subsp. israelensis with chitinase genes from Aeromonas hydrophila and Pseudomonas maltophilia, but expression was rather low. Later, B. thuringiensis subsp. aizawai was transformed with chitinase genes from $B$. circulans. The recombinant had a higher level of chitinase activity and improvements in toxicity against gypsy moth larvae (Lymantria dispar) were observed (Lertcanawanichakul and Wiwat, 2000; Lertcanawanichakul et al., 2004). An interesting observation was that combining $10 \mathrm{mU}$ of $B$. licheniformis chitinases with spores/Cry crystals of $B$. thuringiensis subsp. aizawai against $S$. exigua resulted in a decrease in $\mathrm{LD}_{50}$ by approximately 15 -fold at 7 days, compared to the use of spores/crystals alone. However, when B. thuringiensis subsp. aizawai was 


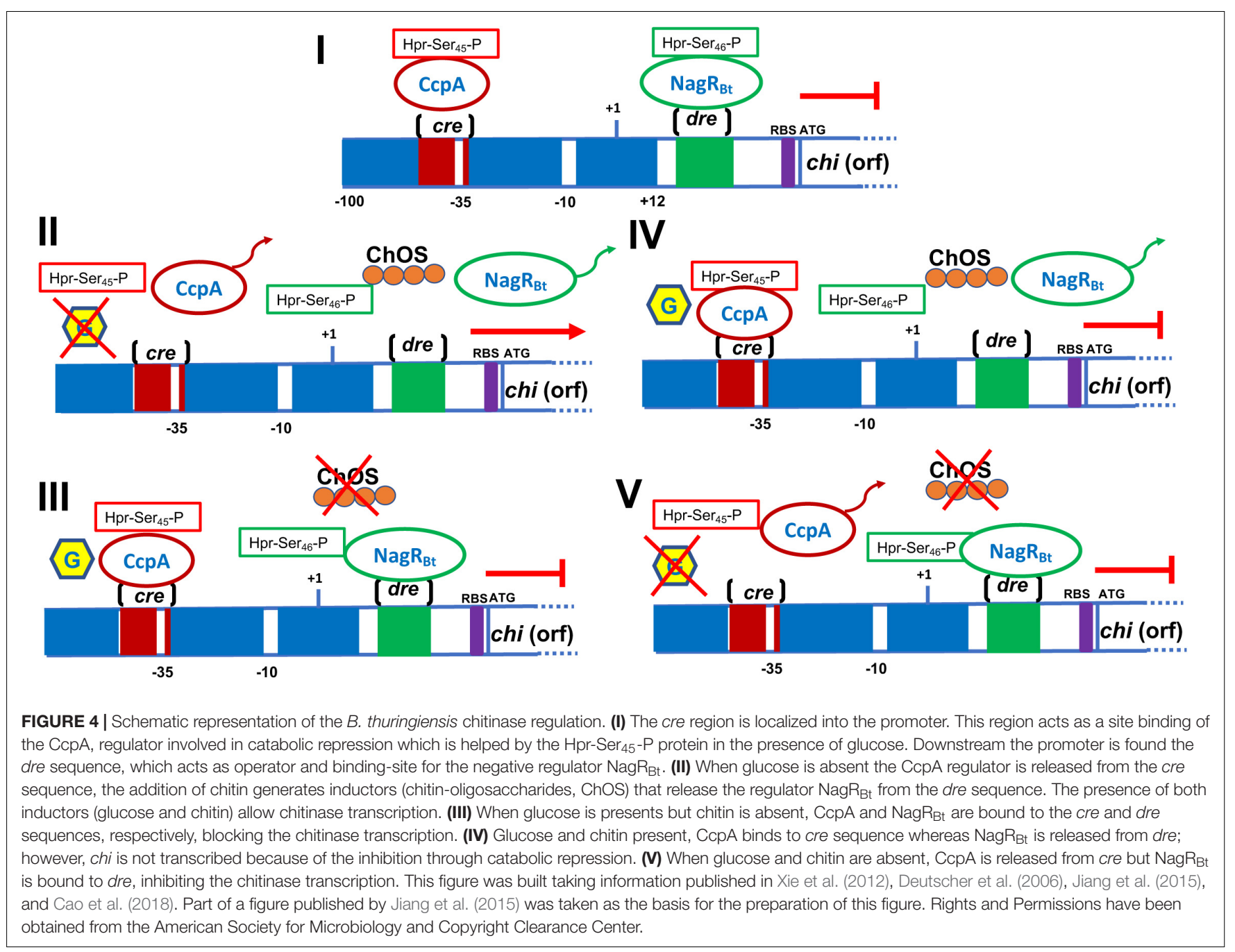

transformed with a chitinase gene from B. licheniformis, a low level of chitinase synthesis was observed with no change in the toxic effect when compared with the parental strain (Tantimavanich et al., 1997). Additionally, a chitinase gene from B. licheniformis TP-1 was used to transform B. thuringiensis subsp. israelensis; the transformant produced a lower number of spores and was less toxic to $A$. aegypti larvae when compared with the parental strain (Sirichotpakorn et al., 2001). These observations indicated that the synthesis of heterologous chitinases in B. thuringiensis requires optimization of expression systems and/or maintaining the efficacy of the enzyme, which unlike Cry proteins is not crystallized to form a stable inclusion prior to delivery to the larval target. In other regards, whereas most studies focused on the use of chitinases combined with spore/crystal mixtures against lepidopterans and dipterans, specifically mosquito larvae, the potential for such a strategy to control coleopterans was also demonstrated. Okay et al. (2008) showed that an anti-coleopteran recombinant $B$. thuringiensis strain 3023 expressing the chiA gene of S. marcescens was 5.2and 1.3-fold more toxic than, respectively, parental 3023 strain and $S$. marcescens.
Because the expression of heterologous chitinases using plasmids can be unstable after a certain number of generations, particularly in the absence of antibiotic selection in the larvae host, the integration of chitinase gene into the bacterial chromosome presented a viable alternative. Thamthiankul et al. (2004) integrated a chitinase gene from B. licheniformis under control of the P19 promoter into the chromosome of B. thuringiensis subsp. aizawai (BTA1) and observed that the growth and sporulation profiles were comparable to the wild-type strain. Preparations of whole culture broth of the recombinant against S. exigua, compared with the wild strain, showed a $2.5 \times$ reduction in the $\mathrm{LC}_{50}$, i.e., from $30.8 \mathrm{microgram} / \mathrm{cm}^{2}$ to $12.2 \mathrm{microgram} / \mathrm{cm}^{2}$. Years later, the same group transformed BTA1 with the chitinase gene of $B$. licheniformis but under the control of the cry11Aa sporulation-dependent promoter. The activity of the recombinant strain against $S$. litura was enhanced by $\sim 4$.6-fold compared to the wild-type strains, a result due to the increase in chitinase synthesis and enzymatic activity which synergized the effect of CrylA (Buasri and Panbangred, 2012). Besides, endogenous chitinases of $B$. thuringiensis subsp. israelensis IPS78 and B. thuringiensis subsp. aizawai HD133 have 
also been implicated in the pathogenicity against, respectively, Culicoides nubeculosus and S. littoralis. This was demonstrated because the use of allosamidin (a chitinase inhibitor) in the bioassays increase the $\mathrm{LD}_{50}$ (i.e., less toxic) compared to a control lacking the inhibitor (Sampson and Gooday, 1998), indicating that chitinase inhibition abolishes the contribution of these enzymes to the toxic effects of Cry proteins. It has been shown that wild-type strains of $B$. thuringiensis produce a basal level of chitinase in culture medium, and that synthesis of the enzyme can be induced or repressed with chitin or glucose, respectively (Barboza-Corona et al., 2009; Xie et al., 2010). The levels of chitinase synthesis can be determined by in vitro assays, qualitatively by the observation of halo formations in solid medium supplemented with colloidal chitin, or quantitatively by measuring reducing sugars and by fluorescence emission using synthetic fluorogenic chitin-derivates when the bacterium is grown in a liquid medium (Barboza-Corona et al., 1999; Liu et al., 2002; Gómez-Ramírez et al., 2004). As endogenous chitinases of $B$. thuringiensis are involved in virulence against insects (Sampson and Gooday, 1998), secreted chitinases present in a culture medium might be useful to increase the insecticidal activity of $B$. thuringiensis. This was verified when secreted chitinases of $B$. thuringiensis in the culture supernatants when mixed with spores/Cry crystals increased toxicity against P. xylostella, S. exigua, and Choristoneura fumiferana (Wiwat et al., 2000; Liu et al., 2002; Vu et al., 2009).

On the other hand, previous studies revealed that B. thuringiensis is antagonistic to phytopathogenic fungi due to the production of lytic enzymes, including chitinases. Therefore, chitinases are also considered as promising biocontrol agents to protect plants, particularly those of high economic value, from infestation and damage by phytopathogenic fungi. The mode of action of $B$. thuringiensis against fungi differs depending on the strains. For example, different morphological effects on fungal cell walls have been noted, such as inhibition of mycelial growth and spore germination, lysis of spores and hyphal tips, and germ tube elongation (Öztopuz et al., 2018). Specifically, the inhibition of phytopathogenic fungi using bacterial suspensions, supernatants, concentrated crude preparations containing chitinases, and purified chitinases of B. thuringiensis have been described. It has also been reported that there is no significant difference in antifungal activities of $B$. thuringiensis between the crude extract and purified chitinase (Morales de la Vega et al., 2006), although Melent'ev et al. (2001) showed that purified chitinase was unable to inhibit the growth of Fusarium oxysporum and Helminthosporium sativum when compared to the activity observed with crude extracts. Isolates of $B$. thuringiensis have shown antifungal potential in dual cultivation assays. For example, Hollensteiner et al. (2017) showed in vitro antagonism toward Verticillium dahlia, a pathogen with a broad host range, including economically important crops such as tomato. The authors suggested that the inhibitory effect on the growth of the phytopathogens was attributed to the presence of chitinases in the supernatant of the bacterial culture. Similar results were obtained with supernatant preparations against Aspergillus niger, A. foetidus, and A. ochraceus (Driss et al., 2005; Öztopuz et al., 2018) in which the antifungal effect was attributed not only to the presence of chitinases but also to a complex of hydrolytic enzymes, including proteases and gluconases. Regardless, inhibitory effects against fungi have been demonstrated using partially purified or purified chitinases of $B$. thuringiensis, and these species-specific enzymes were more effective than those produced by $B$. licheniformis against species of Fusarium, Rhizopus, and Trichoderma (Morales de la Vega et al., 2006; Gomaa, 2012; Mehmood et al., 2015). More recently, a purified chitinase from $B$. thuringiensis subsp. tenebrionis DSM-2803 was shown to adversely affect the growth of Colletotrichum gloeosporioides, a potent phytopathogen that causes "anthracnose" in avocado (Persea americana), and one that is responsible for significant economic loss in México (De la Fuente-Salcido et al., 2016). Other studies have also shown the adverse effect of $B$. thuringiensis chitinases against $F$. oxysporum, the etiological agent of the fungal vascular wilt of date palm, an important traditional crop in North Africa and The Middle East (Ni et al., 2015; Djenane et al., 2017). Phytopathogenic fungi alter plant physiology and cause disease throughout development, including during seed germination. Therefore, the effect of chitinase on germination of seeds infested with phytopathogenic fungi has also been evaluated. Gomaa (2012) showed that crude extracts from $B$. thuringiensis increased the rate of germination of soybean seeds infested with phytopathogens (e.g., Aspergillus terreus) by 7.6-fold when compared to controls. Similar positive effects were observed by Morales de la Vega et al. (2006) with the treatment of seeds infested with Pestalotia sp. and A. niger. Furthermore, Seo et al. (2012) reported that chitinase produced by $B$. thuringiensis GS1 inhibits the growth of Rhizoctonia solani in cucumber plants. Finally, it is also interesting to note that chitinases can induce plant defenses against these microbial pathogens. For example, when rice seedlings were treated with immobilized purified chitinase from B. thuringiensis $\mathrm{H} 3$, an increase in the synthesis of defense enzymes, including peroxidase and phenylalanine ammonia-lyase, was observed (Tang et al., 2012).

While several studies have demonstrated the potential use of $B$. thuringiensis chitinase to control insects and fungi, only a few have been reported on the effect of these enzymes on free-living nematodes such as Caenorhabditis elegans. Studies by Zhang et al. (2014) suggested that the detrimental activity of B. thuringiensis strain 010 against $C$. elegans could be due to the action of chitinases. More recently, a mutant (ChiW50A) of chitinase Chi9602 of B. thuringiensis subsp. tenebrionis YBT-9602 with $\sim 60 \%$ higher enzymatic activity elicited an increase of $\sim 20 \%$ in mortality against C. elegans when compared with the parental strain (Ni et al., 2015). Moreover, nanoparticles made of immobilized $B$. thuringiensis chitinases (i.e., Chi9602) showed enhanced nematicidal effects against C. elegans (Qin et al., 2016).

\section{To Generate Antibacterial Chitin-Derived Oligosaccharides}

Chitinases of $B$. thuringiensis subsp. pakistani (ChiA71), B. thuringiensis (Chi255) and B. thuringiensis subsp. aizawai 
have been shown to hydrolyze colloidal chitin to primarily produce GlcNAc and (GlcNAc) 2 suggesting that these enzymes possess an exo-type chitinase activity (Thamthiankul et al., 2001; Driss et al., 2005; Morales de la Vega et al., 2006). In particular, thin layer chromatography (TLC) demonstrated that ChiA74 of $B$. thuringiensis subsp. kenyae when produced in $E$. coli can generate chitin-derived oligosaccharides (ChOGs) with degrees of polymerization higher than 2, suggesting an endochitinase activity. However, more recently it was shown that purified ChiA74 has a processive activity generating mainly GlcNAc and (GlcNAc) 2 when using colloidal chitin as substrate, suggesting that purified ChiA74 has an exochitinase action and the previous endochitinase activity could be erroneous because the ChiA74 preparation could have been mixed with other enzymes in crude extracts (Casados-Vazquez et al., 2015; Juárez-Hernández et al., 2019). Nevertheless, the resulting ChOGs exhibited antimicrobial activities against a number of clinically significant Grampositive and Gram-negative bacteria, including B. cereus, Listeria monocytogenes, Staphylococcus aureus, Staphylococcus xylosus, Klebsiella pneumoniae, Pseudomonas aeruginosa, Shigella sonnei, Shigella flexneri, and Proteus vulgaris (Barboza-Corona et al., 2008; Ortiz-Rodríguez et al., 2010; Castañeda-Ramírez et al., 2013).

\section{DEVELOPMENT OF RECOMBINANT B. thuringiensis STRAINS EXPRESSING HOMOLOGOUS CHITINASE GENES}

Chitinase genes from $B$. thuringiensis have been used as a resource to generate recombinant strains of the same species. These recombinants can be classified into three categories: (i) strains expressing chitinases that can be secreted and collected from supernatants, (ii) recombinants that synthesize chitinases lacking the secretion signal thereby leading to amorphous intracellular inclusions of the enzyme that are released together with the spores/crystals following autolysis, and (iii) strains producing inclusions composed of the chitinase fused in frame with the C-terminal (crystallization) domain of Cry proteins (Figure 1). Currently, there is no report about the development of $B$. thuringiensis strains with homologous chitinase genes inserted into the chromosome.

Regarding the first category, B. thuringiensis HD73 was transformed with chitinase chiA74 under the control of the wildtype promoter (HD-73-pEHchiA74) or the pcytA-STAB system (HD-73-pEBchiA74) (Casique-Arroyo et al., 2007; BarbozaCorona et al., 2009). The pcytA sequence is composed of three strong sporulation-dependent promoters $\left[\operatorname{BtI}\left(\sigma^{\mathrm{E}}\right), \operatorname{BtII}\left(\sigma^{\mathrm{K}}\right)\right.$, $\left.\operatorname{BtIII}\left(\sigma^{\mathrm{E}}\right)\right]$ which contribute to the high expression level, and the STAB sequence contributes to the stabilization of the mRNA (Park et al., 1998; Sakano et al., 2017). HD-73-pEBchiA74 showed an increase in enzymatic activity of 58- and 362fold higher than HD-73-pEHchiA74 and parental HD-73, respectively, but with a compensating reduction in Cry crystal size and number of viable spores when compared to the wildtype HD73. This, unfortunately, did not increase in toxicity against $P$. xylostella when compared to the parental strain (Casique-Arroyo et al., 2007).

Concerning the second category, the deletion of the secretion signal peptide led to intracellular accumulation and formation of inclusion bodies composed of the enzyme (Barboza-Corona et al., 2014). The premise for developing B. thuringiensis strains that synthesize chitinase as intracellular inclusions is based on the fact the upon autolysis crystals, spores and chitinase inclusion bodies are released simultaneously. For example, a chitinase from $B$. thuringiensis strain 4.0718 under the control of dual overlapping promoters plus Shine-Dalgarno sequence and terminator sequence of $c r y 1 A c 3$ was introduced into $\mathrm{Cry}^{-} \mathrm{B}$, an acrystalliferous $B$. thuringiensis strain that does not produce Cry crystals. Chitinase inclusion bodies were formed and exhibited chitinase activity. When these inclusion bodies were mixed with Cry crystals, an increase in the toxicity of CrylAc against larvae of $S$. exigua and Helicoverpa armigera was observed ( $\mathrm{Hu}$ et al., 2009). As the authors transformed an acrystalliferous strain, they could not study the effect on the production of the insecticidal crystal proteins. To produce chitinase inclusion bodies and Cry crystals in the same $B$. thuringiensis host, chiA74 $\Delta \mathrm{sp}$ lacking the signal peptide sequence under the control of the pchiA wild-type promoter (pEHchiA74 $\Delta \mathrm{sp}$ ) or the pctyA-STAB system (pEBchiA74 $\Delta \mathrm{sp}$ ) was introduced into $B$. thuringiensis kurstaki HD1 and B. thuringiensis subsp. israelensis IPS-82, strains that are commonly used in formulations of commercial

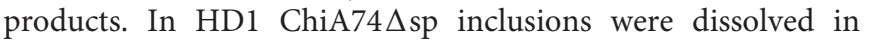
alkali and reducing conditions, similar to Cry crystals, and the enzyme retained its activity in a wide range of $\mathrm{pH}(5-9)$ but showed a drastic reduction $(\sim 70 \%)$ at $\mathrm{pH} 10$. Compared to parental HD1 strain, the recombinant HD1-pEBchiA74 $\Delta$ sp showed a 42-fold increase in chitinase activity and a 3 -fold increase in the number of viable spores, but the bipyramidal Cry crystals were $\sim 30 \%$ smaller. Bioassays against first instar larvae of $M$. sexta with spore-crystals of HD1 or spore-crystalChiA74 $\Delta$ sp inclusions of HD1-pEBchiA74 $\Delta$ sp showed $\mathrm{LC}_{50}$ of 67.30 and $41.45 \mathrm{ng} / \mathrm{cm}^{2}$, respectively (Barboza-Corona et al., 2014). When $B$. thuringiensis subsp. israelensis was transformed with chiA74 $\Delta s p$, the recombinants produced their native Cry crystals composed of Cry4Aa, Cry4Ba, Cry11Aa, and Cyt1Aa and also ChiA74 $\Delta$ sp inclusions. These recombinants showed $\sim 3$-fold increase in both chitinase activity and viable spore count when compared with the parental strain and were twofold more toxic than $B$. thuringiensis subsp. israelensis against fourth instars of A. aegypti larvae (Juárez-Hernández et al., 2015).

Finally, chimeric fusions of chitinase with the C-terminal domains of Cry proteins have been reported in two studies. In the first study, the sequence coding a chitinase of $B$. thuringiensis subsp. kurstaki BUPM255 under the regulation of pBtI-BtII was transcriptionally fused to the C-terminal domain of $c r y 1 A c$ and the construct was used to transform B. thuringiensis BNS33. The recombinant showed a 2.5 -fold increase in chitinase activity and was $1.5 \times$ more toxic to Ephestia kuehniella when compared to the parental strain (Driss et al., 2011). Unfortunately, the authors did not report whether the chimeric protein formed inclusions or retained enzymatic activity in lyophilized 
preparations. A similar study was performed by GonzálezPonce et al. (2017), where the chiA74 gene lacking its secretion signal peptide sequence ( $c h i A 74 \Delta s p$ ) was fused in frame with the sequence coding for the C-terminal crystallization domain and transcription terminator of $c r y 1 A c$, under the regulation of spcytA-p/STAB-SD promoter system, and the construct was used to transform B. thuringiensis subsp. kurstaki HD73. Amorphous inclusions apparently composed of the chimera and native bipyramidal CrylAc crystals were observed. The chitinase activity of purified Cry1Ac/amorphous inclusions was 51-fold higher when compared to purified Cry1Ac inclusions of parental HD73. Bioassays against larvae of S. frugiperda with spore/crystals of HD73 or spore-crystals-ChiA74 $\Delta$ sp chimeric inclusions of recombinant HD73 showed a reduction of $30 \%$ in the $\mathrm{LC}_{50}$ 's when compared to wild-type HD73, indicating that the enhancement in toxicity directly correlated to the presence of the atypical amorphous component.

\section{FUTURE PERSPECTIVE}

Bacillus thuringiensis is a fascinating microbe for several reasons, but primarily for its ability to produce a plethora of molecules that have applied or potential applied value. Unequivocally, this microbe should be viewed as a microbial factory that can be engineered and exploited for simultaneous production of Cry and Cyt proteins, VIPs, parasporins, chitinases, and other metabolites that target vectors of human diseases, cancers, clinically significant microbial pathogens, and agricultural pest.

In spite of recent advances in the study of the B. thuringiensis chitinases, several issues need to be resolved. In particular, with regard to its entomocidal potential, it has been demonstrated that chitinases from $B$. thuringiensis increase the toxic effect of Cry proteins, but there is no evidence to show whether these enzymes act synergistically or merely potentiate the activity of Cry. There appears to be little or no evidence to support a hypothesis that substantial increases in chitinase production and enzymatic activity translate to substantial decreases in $\mathrm{LC}_{50}$ s. In this regard, definitive studies are required to determine the fate of chitinases in the insect midgut after ingestion. Are these enzymes relatively stable or are they rapidly degraded by digestive proteases? Indeed, it is not clear whether the chitinolytic activity of a particular chitinase is insect-species specific, or whether optimal catalysis for the enzyme is dependent on the organization and variation of chitin in the peritrophic membrane. Our phylogenetic analysis suggests that chitinases from $B$. thuringiensis can be grouped in different clusters, but whether members in these clusters have species-specific targets requires an extensive study that realistically will not be completed in the near future. Assuming that chitinases are stable and active in the physical and biochemical environment of the midgut, at least for the time required for activation of Cry toxins, the questions of whether inclusions of the enzyme produced in microbial factories (including $B$. thuringiensis) dissolve efficiently in vivo, and if the solubilized forms of the enzyme refold properly for effective catalysis are interesting and worth addressing. The extent of antifungal and nematicidal effects of chitinases produced by $B$. thuringiensis remains questionable in our view. More focused studies on a variety of these enzymes assayed on individual fungal and nematode species could provide valuable insights into selecting the best, or suitable, candidates for further research and development. Moreover, basic molecular research is required to elucidate the translocation mechanism(s) of chitinases in B. thuringiensis, although it is likely that a system analogous to that in E. coli is involved, based on the observation that chitinases of $B$. thuringiensis origin are secreted by this Gram-negative bacterium. Moreover, whether the chitinases of B. thuringiensis have a processive or non-processive mechanism of chitin hydrolysis needs to be determined.

Finally, due to the structural differences and characteristics that chitinases have, their use in specific practical applications can be difficult to determine and optimize (Oyeleye and Normi, 2018). However, we believe that many of these issues will ultimately be resolved and that the recent structural analyses (Packer and Liu, 2015; Juárez-Hernández et al., 2019) will be indispensable toward this end. With this knowledge, and with the use of genome editing technologies and new synthetic biology and computational tools, the performance of chitinases could be improved. For instance, due to the modularity of chitinases, the creation of new synthetic chitinases derived from a combination of different protein domains could enable the creation of new tailor-made chitinases with new functions. These new synthetic chitinases could then be used for specific biotechnological applications and potentially help increase the market demand for chitinolytic enzymes derived from microbial cell factories like B. thuringiensis.

\section{AUTHOR CONTRIBUTIONS}

SM-Z, UB-C, GH-G, DB, and JB-C wrote the manuscript and making substantial contributions to the work. All authors read and approved the final version of the manuscript.

\section{FUNDING}

This research was supported by Grant SEP-CONACyT (258220) Mexico, to JB-C.

\section{ACKNOWLEDGMENTS}

$\mathrm{SM}-\mathrm{Z}$ is a doctoral student in the graduate program in BioSciences of the University of Guanajuato (UG), Mexico, scholarship from CONACyT. UB-P is a M.Sc. student in Systems and Synthetic Biology at The University of Edinburgh, United Kingdom, and scholarship from CONACyT, Mexico. 


\section{REFERENCES}

Argola-Filho, R. C., and Loguercio, L. L. (2014). Bacillus thuringiensis is an environmental pathogen and host-specificity has developed as an adaptation to human-generated ecological niches. Insects 5, 62-91. doi: 10.3390/ insects5010062

Arora, N., Ahmad, T., Rajagopal, R., and Bhatnagar, R. K. (2003). A constitutively expressed $36 \mathrm{kDa}$ exochitinase from Bacillus thuringiensis HD-1. Biochem. Biophys. Res. Commun. 307, 620-625. doi: 10.1016/s0006-291x(03)01228-2

Arora, N., Sachdev, B., Gupta, R., Vimala, Y., and Bhatnagar, R. K. (2013). Characterization of a chitin-binding protein from Bacillus thuringiensis HD-1. PLoS One 8:e66603. doi: 10.1371/journal.pone.0066603

Azizoglu, U. (2019). Bacillus thuringiensis as a biofertilizer and biostimulator: a mini-review of the little-known plant growth-promoting properties of Bt. Curr. Microbiol. 76, 1379-1385. doi: 10.1007/s00284-019-01705-9

Barboza-Corona, J. E., Contreras, J. C., Velázquez-Robledo, R., Bautista-Justo, M., Gómez-Ramírez, M., Cruz-Camarillo, R., et al. (1999). Selection of chitinolytic strains of Bacillus thuringiensis. Biotechnol. Lett. 12, 1125-1129.

Barboza-Corona, J. E., Delgadillo-Ángeles, J. L., Castañeda-Ramírez, J. C., Barboza-Pérez, U. E., Casados-Vázquez, L. E., Bideshi, D. K., et al. (2014). Bacillus thuringiensis subsp. kurstaki HD1 as a factory to synthesize alkalilabile ChiA74 $\Delta$ sp chitinase inclusions, Cry crystals and spores for applied use. Microb. Cell Fact. 13:15. doi: 10.1186/1475-2859-13-15

Barboza-Corona, J. E., Nieto-Mazzocco, E., Velázquez-Robledo, R., SalcedoHernández, R., Bautista, M., Jiménez, B., et al. (2003). Cloning, sequencing, and expression of the chitinase gene chiA74 from Bacillus thuringiensis. Appl. Environ. Microbiol. 69, 1023-1029. doi: 10.1128/aem.69.2.1023-1029.2003

Barboza-Corona, J. E., Ortiz-Rodríguez, T., de la Fuente-Salcido, N., Ibarra, J., Bideshi, D. K., and Salcedo-Hernández, R. (2009). Hyperproduction of chitinase influences crystal toxin synthesis and sporulation of Bacillus thuringiensis. Antonie Van Leeuwenhoek 96, 31-42. doi: 10.1007/s10482-009-9332-9

Barboza-Corona, J. E., Reyes-Rios, D. M., Salcedo-Hernández, R., and Bideshi, D. K. (2008). Molecular and biochemical characterization of an endochitinase (ChiA-HD73) from Bacillus thuringiensis subsp. kurstaki HD-73. Mol. Biotechnol. 39, 29-37. doi: 10.1007/s12033-007-9025-4

Bazinet, A. L. (2017). Pan-genome and phylogeny of Bacillus cereus sensu lato. BMC Evol. Biol. 17:176. doi: 10.1186/s12862-017-1020-1

Bertram, R., Rigali, S., Wood, N., Lulko, A. T., Kuipers, O. P., and Titgemeyer, F. (2011). Regulon of the $N$-acetylglucosamine utilization regulator NagR in Bacillus subtilis. J. Bacteriol. 193, 3525-3536. doi: 10.1128/JB.00264-11

Buasri, W., and Panbangred, W. (2012). Large crystal toxin formation in chromosomally engineered Bacillus thuringiensis subsp. aizawai due to $\sigma \mathrm{E}$ accumulation. Appl. Environ. Microbiol. 78, 1682-1691. doi: 10.1128/AEM. 06505- 11

Cao, Z. L., Tan, T. T., Zhang, Y. L., Han, L., Hou, X. Y., Ma, H. Y., et al. (2018). NagRBt is a pleiotropic and dual transcriptional regulator in Bacillus thuringiensis. Front. Microbiol. 11:1899. doi: 10.3389/fmicb.2018.01899

Casados-Vazquez, L. E., Avila-Cabrera, S., Bideshi, D. K., and Barboza-Corona, J. E. (2015). Heterologous expression, purification and biochemical characterization of endochitinase ChiA74 from Bacillus thuringiensis. Protein Expr. Purif. 109, 99-105. doi: 10.1016/j.pep.2014.11.015

Casados-Vázquez, L. E., Bideshi, K. D., and Barboza-Corona, J. E. (2017). The thnR gene is a negative transcription regulator of the thurincin $\mathrm{H}$ genetic cassette in Bacillus thuringiensis subsp. morrisoni. Arch. Microbiol. 199, 385-390. doi: 10.1007/s00203-016-1298-1

Casados-Vázquez, L. E., Bideshi, K. D., and Barboza-Corona, J. E. (2018). Regulator ThnR and the ThnDE ABC transporter proteins confer autoimmunity to thurincin H in Bacillus thuringiensis. Antonie Van Leeuwenhoek 111, 23492360. doi: 10.1007/s10482-018-1124-7

Casique-Arroyo, G., Bideshi, D., Salcedo-Hernández, R., and Barboza-Corona, J. E. (2007). Development of a recombinant strain of Bacillus thuringiensis subsp. kurstaki HD-73 that produces the endochitinase ChiA74. Antonie Van Leeuwenhoek 92, 1-9. doi: 10.1007/s10482-006-9127-1

Castañeda-Ramírez, C., De la Fuente-Salcido, N. M., Salcedo-Hernández, R., León-Galván, F., Bideshi, D. K., and Barboza-Corona, J. E. (2013). High-level synthesis of endochitinase ChiA74 in Escherichia coli K12 and its promising potential for use in biotechnology. Folia Microbiol. 58, 455-462. doi: 10.1007/ s12223-013-0229-7
Chen, Y. L., Lu, W., Chen, Y. H., Xiao, L., and Cai, J. (2007). Cloning, expression and sequence analysis of chiA, chiB in Bacillus thuringiensis subsp. colmeri 15A3. Wei Sheng Wu Xue Bao 47, 843-848.

Chigalel̆chik, A. G. (1976). Chitinases of Bacillus thuringiensis. Mikrobiologiia 45, 966-972.

Colson, S., Stephan, J., Hertrich, T., Saito, A., van Wezel, G. P., Titgemeyer, F., et al. (2007). Conserved cis-acting elements upstream of genes composing the chitinolytic system of Streptomycetes are DasR-responsive elements. J. Mol. Microbiol. Biotechnol. 12, 60-66. doi: 10.1159/000096460

De la Fuente-Salcido, N. M., Casados-Vázquez, L. E., and Barboza-Corona, J. E. (2013). Bacteriocins of Bacillus thuringiensis can expand the potential of this bacterium to other areas rather than limit its use only as microbial insecticide. Can. J. Microbiol. 59, 515-522. doi: 10.1139/cjm-2013-0284

De la Fuente-Salcido, N. M., Casados-Vázquez, L. E., García-Pérez, A. P., Barboza-Pérez, U. E., Bideshi, D. K., Salcedo-Hernández, R., et al. (2016). The endochitinase ChiA Btt of Bacillus thuringiensis subsp. tenebrionis DSM2803 and its potential use to control the phytopathogen Colletotrichum gloeosporioides. Microbiologyopen 5, 819-829. doi: 10.1002/mbo3.372

Deutscher, J., Francke, C., and Postma, P. W. (2006). How phosphotransferase system-related protein phosphorylation regulates carbohydrate metabolism in bacteria. Microbiol. Mol. Biol. Rev. 70, 939-1031. doi: 10.1128/mmbr.00024-06

Djenane, Z., Nateche, F., Amziane, M., Gomis-Cebolla, J., El-Aichar, F., Khorf, H., et al. (2017). Assessment of the antimicrobial activity and the entomocidal potential of Bacillus thuringiensis isolates from Algeria. Toxins 9:139. doi: 10. 3390/toxins9040139

Downing, K. J., Leslie, G., and Thomson, J. A. (2000). Biocontrol of the sugarcane borer Eldana saccharina by expression of the Bacillus thuringiensis cry $1 \mathrm{Ac} 7$ and Serratia marcescens chiA genes in sugarcane-associated bacteria. Appl. Environ. Microbiol. 66, 2804-2810. doi: 10.1128/aem.66.7.2804-2810.2000

Drahl, C. (2019). How seafood shells could help solve the plastic waste problem. Sciencenews 195:8. doi: 10.1016/s0958-2118(11)70035-0

Driss, F., Kallassy-Awad, M., Zouari, N., and Jaoua, S. (2005). Molecular characterization of a novel chitinase from Bacillus thuringiensis subsp. kurstaki. J. Appl. Microbiol. 99, 945-953. doi: 10.1111/j.1365-2672.2005.02639.x

Driss, F., Rouis, S., Azzouz, H., Tounsi, S., Zouari, N., and Jaoua, S. (2011). Integration of a recombinant chitinase into Bacillus thuringiensis parasporal insecticidal crystal. Curr. Microbiol. 62, 281-288. doi: 10.1007/s00284-0109704-4

Felsenstein, J. (1985). Confidence limits on phylogenies: an approach using the bootstrap. Evolution 39, 783-791. doi: 10.1111/j.1558-5646.1985.tb00420.x

Gomaa, E. K. (2012). Chitinase production by Bacillus thuringiensis and Bacillus licheniformis: their potential in antifungal biocontrol. J. Microbiol. 50, 103-111. doi: $10.1007 / \mathrm{s} 12275-012-1343-y$

Gómez-Ramírez, M., Rojas-Avelizapa, L. I., Rojas-Avelizapa, N. G., and CruzCamarillo, R. (2004). Colloidal chitin stained with Remazol Brilliant Blue $\mathrm{R}$, a useful substrate to select chitinolytic microorganisms and to evaluate chitinases. J. Microbiol. Methods 56, 213-219. doi: 10.1016/j.mimet.2003. 10.011

González-Ponce, K. S., Casados-Vázquez, L. E., Lozano-Sotomayor, P., Bideshi, D. K., Del Rincón-Castro, M. C., and Barboza-Corona, J. E. (2019). Expression of ChiA74 $\Delta \mathrm{sp}$ and its truncated versions in Bacillus thuringiensis HD1 using a vegetative promoter maintains the integrity and toxicity of native CrylA toxins. Int. J. Biol. Macromol. 124, 80-87. doi: 10.1016/j.ijbiomac.2018.11.173

González-Ponce, K. S., Casados-Vázquez, L. E., Salcedo-Hernández, R., Bideshi, D. K., Rincón-Castro, M. C., and Barboza-Corona, J. E. (2017). Recombinant Bacillus thuringiensis subsp. kurstaki HD73 strain that synthesizes CrylAc and chimeric ChiA74 $\Delta$ sp chitinase inclusions. Arch. Microbiol. 199, 627-633. doi: 10.1007/s00203-017-1339-4

Guttmann, D. M., and Ellar, D. J. (2000). Phenotypic and genotypic comparisons of 23 strains from the Bacillus cereus complex for a selection of known and putative B. thuringiensis virulence factors. FEMS Microbiol. Lett. 188, 7-13. doi: 10.1016/s0378-1097(00)00200-7

Haldenwang, W. D. (1995). The sigma factors of Bacillus subtilis. Microbiol. Rev. $59,1-30$.

Herth, W., Mulisch, M., and Zugenmaier, P. (2011). "Comparison of chitin fibril structure and assembly in three unicellular organisms," in Chitin in Nature and Technology, eds R. Muzzarelli, C. Jeuniaux, and G. W. Gooday, (Boston, MA: Springer). doi: 10.1007/978-1-4613-2167-5_15 
Hollensteiner, J., Wemheuer, F., Harting, R., Kolarzyk, A. M., Diaz Valerio, S. M., Poehlein, A., et al. (2017). Bacillus thuringiensis and Bacillus weihenstephanensis inhibit the growth of phytopathogenic Verticillium species. Front. Microbiol. 17:2171. doi: 10.3389/fmicb.2016.02171

Honda, S., Kunii, T., Nohara, K., Wakita, S., Sugahara, Y., Kawakita, M., et al. (2017). Characterization of a Bacillus thuringiensis chitinase that binds to cellulose and chitin. AMB Express 7:51. doi: 10.1186/s13568-017-0352-y

Hu, S. B., Liu, P., Ding, X. Z., Yan, L., Sun, Y. J., Zhang, Y. M., et al. (2009). Efficient constitutive expression of chitinase in the mother cell of Bacillus thuringiensis and its potential to enhance the toxicity of CrylAc protoxin. Appl. Microbiol. Biotechnol. 82, 1157-1167. doi: 10.1007/s00253-009-1910-2

Jiang, K., Li, L. N., Pan, J. H., Wang, T. T., Chen, Y. H., and Cai, J. (2015). YvoA and CcpA repress the expression of chiB in Bacillus thuringiensis. Appl. Environ. Microbiol. 81, 6548-6557. doi: 10.1128/AEM.01549-15

Jouzani, G. S., Valijanian, E., and Sharafi, R. (2017). Bacillus thuringiensis: a successful insecticide with new environmental features and tidings. Appl. Microbiol. Biotechnol. 101, 2691-2711. doi: 10.1007/s00253-017-8175-y

Juárez-Hernández, E. O., Casados-Vázquez, L. E., Bideshi, D. K., SalcedoHernández, R., and Barboza-Corona, J. E. (2017). Role of the C-terminal and chitin insertion domains on enzymatic activity of endochitinase ChiA74 of Bacillus thuringiensis. Int. J. Biol. Macromol. 102, 52-59. doi: 10.1016/j.ijbiomac. 2017.03.191

Juárez-Hernández, E. O., Casados-Vázquez, L. E., Brieba, L. G., Torres-Larios, A., Jimenez-Sandoval, P., and Barboza-Corona, J. E. (2019). The crystal structure of the chitinase ChiA74 of Bacillus thuringiensis has a multidomain assembly. Sci. Rep. 9:2591. doi: 10.1038/s41598-019-39464-z

Juárez-Hernández, E. O., Casados-Vázquez, L. E., Del Rincón-Castro, M. C., Salcedo-Hernández, R., Bideshi, D. K., and Barboza-Corona, J. E. (2015). Bacillus thuringiensis subsp. israelensis producing endochitinase ChiA $74 \Delta \mathrm{sp}$ inclusions and its improved activity against Aedes aegypti. J. Appl. Microbiol. 119, 1692-1699. doi: 10.1111/jam.12962

Kaya, M., Mujtaba, M., Ehrlich, H., Salaberria, A. M., Baran, T., Amemiya, C. T., et al. (2017). On chemistry of $\gamma$-chitin. Carbohydr. Polym. 176, 177-186. doi: 10.1016/j.carbpol.2017.08.076

Kumar, S., Stecher, G., Li, M., Knyaz, C., and Tamura, K. (2018). MEGA X: molecular evolutionary genetics analysis across computing platforms. Mol. Biol. Evol. 35, 1547-1549. doi: 10.1093/molbev/msy096

Lacey, L. A., Grzywacz, D., Shapiro-Ilan, D. I., Frutos, R., Brownbridges, M., and Gottel, M. S. (2015). Insect pathogens as biological control agents: back to the future. J. Invertebr. Pathol. 132, 1-41. doi: 10.1016/j.jip.2015.07.009

Lee, H., Churey, J. J., and Worobo, R. W. (2009). Biosynthesis and transcriptional analysis of thurincin $\mathrm{H}$, a tandem repeated bacteriocin genetic locus, produced by Bacillus thuringiensis SF361. FEMS Microbiol. Lett. 299, 205-213. doi: 10. $1111 /$ j.1574-6968.2009.01749.x

Lertcanawanichakul, M., and Wiwat, C. (2000). Improved shuttle vector for expression of chitinase gene in Bacillus thuringiensis. Lett. Appl. Microbiol. 31, 123-128. doi: 10.1046/j.1365-2672.2000.00777.x

Lertcanawanichakul, M., Wiwat, C., Bhumiratana, A., and Dean, D. H. (2004). Expression of chitinase-encoding genes in Bacillus thuringiensis and toxicity of engineered B. thuringiensis subsp. aizawai toward Lymantria dispar larvae. Curr. Microbiol. 48, 175-181. doi: 10.1007/s00284-003-4119-0

Li, D., and Li, A. (2009). "Current advances in fungal chitinases," in Applied Mycology, eds M. Rai, and P. D. Bridge, (Wallingford: CABI), 268. doi: 10.1079/ 9781845935344.0268

Li, H., and Greene, L. H. (2010). Sequence and structural analysis of the chitinase insertion domain reveals two conserved motifs involved in chitin-binding. PLoS One 5:e8654. doi: 10.1371/journal.pone.0008654

Lin, Y., and Xiong, G. (2004). Molecular cloning and sequence analysis of the chitinase gene from Bacillus thuringiensis serovar alesti. Biotechnol. Lett. 26, 635-639. doi: 10.1023/b:bile.0000023021.50213.ed

Liu, M., Cai, Q. X., Liu, H. Z., Zhang, B. H., Yan, J. P., and Yuan, Z. M. (2002). Chitinolytic activities in Bacillus thuringiensis and their synergistic effects on larvicidal activity. J. Appl. Microbiol. 93, 374-379. doi: 10.1046/j.1365-2672. 2002.01693.x

Lobo, M. D. P., Silva, F. D. A., Landim, P. G. C., Cruz, P. R., Brito, T. L., Medeiros, S. C., et al. (2013). Expression and efficient secretion of a functional chitinase from Chromobacterium violaceum in Escherichia coli. BMC Biotechnol. 13:46. doi: $10.1186 / 1472-6750-13-46$
Malovichko, Y., Nizhnikov, A. A., and Antonets, K. S. (2019). Repertoire of the Bacillus thuringiensis virulence factors unrelated to major classes of protein toxins and its role in specificity of host-pathogen interactions. Toxins 11:347. doi: 10.3390/toxins1 1060347

Mehmood, M. A., Latif, M., Hussain, K., Gull, M., Latif, F., and Rajoka, M. I. (2015). Heterologous expression of the antifungal $\beta$-chitin binding protein CBP24 from Bacillus thuringiensis and its synergistic action with bacterial chitinases. Protein Pep. Lett. 22, 39-44. doi: 10.2174/0929866521666140901143114

Melent'ev, A. I., Aktuganov, G. E., and Galimzyanova, N. F. (2001). The role of chitinase in the antifungal activity of Bacillus sp. 739. Mikrobiologiya 70, 636-641.

Mendoza-Almanza, G., Rocha-Zavaleta, L., Aguilar-Zacarías, C., Ayala-Luján, J., and Olmos, J. (2019). CrylA proteins are cytotoxic to HeLa but not to SiHa cervical cancer cells. Curr. Pharm. Biotechnol. 20, 1018-1027. doi: 10.2174/ 1389201020666190802114739

Morales de la Vega, L., Barboza-Corona, J. E., Aguilar-Uscanga, M. G., and Ramírez-Lepe, M. (2006). Purification and characterization of an exochitinase from Bacillus thuringiensis ssp. aizawai and its action against phytopathogenic fungi. Can. J. Microbiol. 52, 651-657. doi: 10.1139/w06-019

Morganti, J. (2012). Nanoparticles and nanostructures man-made or naturally recovered: the biomimetic activity of chitin nanofibrils. J. Nanomater. Mol. Nanotechnol. 1:2. doi: 10.4172/2324-8777.1000101

Nei, M., and Kumar, S. (2000). Molecular Evolution and Phylogenetics. New York, NY: Oxford University Press.

Ni, H., Zeng, X., Quin, X., Sun, S., Zhang, X., Zhao, X., et al. (2015). Molecular docking and site-directed mutagenesis of a Bacillus thuringiensis chitinase to improve chitinolytic, synergistic lepidopteran-larvicidal and nematicidal activities. Int. J. Biol. Sci. 11, 304-315. doi: 10.7150/ijbs. 10632

Ohba, M., Mizuki, E., and Uemori, A. (2009). Parasporin, a new anticancer protein group from Bacillus thuringiensis. Anticancer Res. 29, 427-433.

Okay, S., Tefon, B. E., Ozkan, M., and Ozcengiz, G. (2008). Expression of chitinase A (chiA) gene from a local isolate of Serratia marcescens in Coleoptera-specific Bacillus thuringiensis. J. Appl. Microbiol. 104, 161-170.

Ortiz-Rodríguez, T., de la Fuente-Salcido, N., Bideshi, D. K., SalcedoHernández, R., and Barboza-Corona, J. E. (2010). Generation of chitin-derived oligosaccharides toxic to pathogenic bacteria using ChiA74, an endochitinase native to Bacillus thuringiensis. Lett. Appl. Microbiol. 51, 184-190. doi: 10.1111/ j.1472-765X.2010.02876.x

Oyeleye, A., and Normi, Y. M. (2018). Chitinase: diversity, limitations, and trends in engineering for suitable applications. Biosci. Rep. 38:BSR2018032300. doi: 10.1042/BSR20180323

Öztopuz, Ö., Pekin, G., Park, R. D., and Eltem, R. (2018). Isolation and evaluation of new antagonist Bacillus strains for the control of pathogenic and mycotoxigenic fungi of fig orchards. Appl. Biochem. Biotechnol. 186, 692-711. doi: 10.1007/s12010-018-2764-9

Packer, M. S., and Liu, D. R. (2015). Methods for the directed evolution of proteins. Nat. Rev. Genet. 16, 379-394. doi: 10.1038/nrg3927

Palma, L., Muñoz, D., Berry, C., Murillo, J., and Caballero, P. (2014). Bacillus thuringiensis toxins: an overview of their biocidal activity. Toxins 6, 3296-3325. doi: 10.3390/toxins6123296

Park, H. W., Ge, B., Bauer, L. S., and Federici, B. A. (1998). Optimization of Cry3A yields in Bacillus thuringiensis by use of sporulation-dependent promoters in combination with the STAB-SD mRNA sequence. Appl. Environ. Microbiol. 64, 3932-3938.

Qin, X., Xiang, X., Sun, X., Ni, H., and Li, L. (2016). Preparation of nanoscale Bacillus thuringiensis chitinases using silica nanoparticles for nematicide delivery. Int. J. Biol. Macromol. 82, 13-21. doi: 10.1016/j.ijbiomac.2015. 10.030

Regev, A., Keller, M., Strizhov, N., Sneh, B., Prudovsky, E., Chet, I., et al. (1996). Synergistic activity of a Bacillus thuringiensis delta-endotoxin and a bacterial endochitinase against Spodoptera littoralis larvae. Appl. Environ. Microbiol. 62, 3581-3586.

Ren, J., Wen, L., Gao, X., Jin, C., Xue, Y., and Yao, X. (2009). Illustrator of protein domain structures. Cell Res. 19, 271-273. doi: 10.1038/cr.2009.6

Rosas-García, N. M., Fortuna-González, J. M., and Barboza-Corona, J. E. (2013). Characterization of the chitinase gene in Bacillus thuringiensis mexican isolates. Folia Microbiol. 58, 483-490. doi: 10.1007/s12223-013-0233-y 
Sakano, Y., Park, H. W., Bideshi, D. K., Ge, B., and Federici, B. A. (2017). Contributions of $5^{\prime}$-UTR and $3^{\prime}$-UTR cis elements to Cyt1Aa synthesis in Bacillus thuringiensis subsp. israelensis. J. Invertebr. Pathol. 149, 66-75. doi: 10.1016/j.jip.2017.08.002

Sampson, M. N., and Gooday, G. W. (1998). Involvement of chitinases of Bacillus thuringiensis during pathogenesis in insects. Microbiology 144(Pt 8), 2189-2194. doi: 10.1099/00221287-144-8-2189

Seo, D. J., Nguyen, D. M., Song, Y. S., and Jungo, W. J. (2012). Induction of defense response against Rhizoctonia solani in cucumber plants by endophytic bacterium Bacillus thuringiensis GS1. J. Microbiol. Biotechnol. 22, 407-415. doi: 10.4014/jmb.1107.07027

Sirichotpakorn, N., Rongnoparut, P., Choosang, K., and Panbangred, W. (2001). Coexpression of chitinase and the cry11Aal toxin genes in Bacillus thuringiensis serovar israelensis. J. Invertebr. Pathol. 78, 160-169. doi: 10.1006/jipa.2001.5058

Smirnoff, W. A. (1974). The symptoms of infection by Bacillus thuringiensis + chitinase formulation in larvae of Choristoneura fumiferana. J. Invertebr. Pathol. 23, 397-399. doi: 10.1016/0022-2011(74)90108-6

Svitil, A., and Kirchman, D. (1998). A chitin-binding domain in a marine bacterial chitinase and other microbial chitinases: implications for the ecology and evolution of 1,4-b-glycanase. Microbiology 144, 1299-1308. doi: 10.1099/ 00221287-144-5-1299

Tang, Y., Zou, J., Zhang, L., Li, Z., Ma, C., and Ma, N. (2012). Anti-fungi activities of Bacillus thuringiensis $\mathrm{H} 3$ chitinase and immobilized chitinase particles and their effects to rice seedling defensive enzymes. J. Nanosci. Nanotechnol. 12, 8081-8086. doi: 10.1166/jnn.2012.6639

Tantimavanich, S., Pantuwatana, S., Bhumiratana, A., and Panbangred, W. (1997). Cloning of a chitinase gene into Bacillus thuringiensis subsp. aizawai for enhanced insecticidal activity. J. Gen. Appl. Microbiol. 43, 341-347. doi: 10. 2323/jgam.43.341

Thamthiankul, S., Moar, W. J., Miller, M. E., and Panbangred, W. (2004). Improving the insecticidal activity of Bacillus thuringiensis subsp. aizawai against Spodoptera exigua by chromosomal expression of a chitinase gene. Appl. Microbiol. Biotechnol. 65, 183-192.

Thamthiankul, S., Suan-Ngay, S., Tantimavanich, S., and Panbangred, W. (2001). Chitinase from Bacillus thuringiensis subsp. pakistani. Appl. Microbiol. Biotechnol. 56, 395-401. doi: 10.1007/s002530100630

Valk, V., van der Kaaij, R. M., and Dijkhuizen, L. (2017). The evolutionary origin and possible functional roles of FNIII domains in two Microbacterium aurum B8.A granular starch degrading enzymes, and in other carbohydrate acting enzymes. Amylase 1, 1-11. doi: 10.1515/amylase-2017-0001

Van Aalten, D. M., Synstad, B., Brurberg, M. B., Hough, E., Riise, B. W., Eijsink, V. G. H., et al. (2000). Structure of a two-domain chitotriosidase from Serratia marcescens at 1.9-A resolution. Proc. Natl. Acad. Sci. U.S.A. 97, 5842-5847. doi: 10.1073/pnas.97.11.5842

Vu, K. D., Yan, S., Tyagi, R. D., Valéro, J. R., and Surampalli, R. Y. (2009). Induced production of chitinase to enhance entomotoxicity of Bacillus thuringiensis employing starch industry wastewater as a substrate. Bioresour. Technol. 100, 5260-5269. doi: 10.1016/j.biortech.2009.03.084

Watanabe, T., Ito, Y., Hachimoto, M., Sekine, S., and Tanaka, H. (1994). The role of the C-terminal domain and type III domains chitinase A-1 from Bacillus circulans WL-12 in chitin degradation. J. Bacteriol. 176, 4465-4472. doi: 10. 1128/jb.176.15.4465-4472.1994
Watanabe, T., Kobori, K., Miyashita, K., Fujii, T., Sakai, H., Uchida, M., et al. (1993). Identification of glutamic acid 201 and aspartic 200 in chitinase A1 of Bacillus circulans WL-12 as essential residues for chitinase activity. J. Biol. Chem. 68, 18567-18572.

Wertz, J. L., Deleu, M., Coppée, S., and Richel, A. (eds). (2017). “Carbohydrateactive enzymes," in Hemicelluloses and Lignin in Biorefineries: Green Chemistry and Chemical Engineering, (Boca Raton, FL: CRC Press).

Wiwat, C., Lertcanawanichakul, M., Siwayapram, P., Pantuwatana, S., and Bhumiratana, A. (1996). Expression of chitinase-encoding genes from Aeromonas hydrophila and Pseudomonas maltophilia in Bacillus thuringiensis subsp. israelensis. Gene 179, 119-126. doi: 10.1016/s0378-1119(96)00575-6

Wiwat, C., Thaithanun, S., Pantuwatana, S., and Bhumiratana, A. (2000). Toxicity of chitinase-producing Bacillus thuringiensis ssp. kurstaki HD-1 (G) toward Plutella xylostella. J. Invertebr. Pathol. 76, 270-277. doi: 10.1006/jipa.2000.4976

Wu, M. L., Chuang, Y. C., Chen, J. P., Chen, C. S., and Chang, M. C. (2001). Identification and characterization of the three chitin-binding domains within the multidomain chitinase Chi92 from Aeromonas hydrophila JP101. Appl. Environ. Microbiol. 67, 5100-5106. doi: 10.1128/AEM.67.11.5100-5106. 2001

Xie, C., Chen, Y., Cai, J., Liu, C., and Chen, Y. (2010). Essential expression and inducible synthesis polymorphism of chitinase in Bacillus thuringiensis. Sheng Wu Gong Cheng Xue Bao 26, 1532-1538.

Xie, C. C., Luo, Y., Chen, Y. H., and Cai, J. (2012). Construction of a promoterprobe vector for Bacillus thuringiensis: the identification of cis-acting elements of the chiA locus. Curr. Microbiol. 64, 492-500. doi: 10.1007/s00284-0120100-0

Zhang, A., He, Y., Wei, G., Zhou, J., Dong, W., Chen, K., et al. (2018). Molecular characterization of a novel chitinase $\mathrm{CmChi1}$ from Chitinolyticbacter meiyuanensis SYBC-H1 and its use in N-acetyl-d-glucosamine production. Biotechnol. Biofuels 11:179. doi: 10.1186/s13068-018-1169-X

Zhang, L., Yu, J., Xie, Y., Lin, H., Huang, Z., Xu, L., et al. (2014). Biological activity of Bacillus thuringiensis (Bacillales: Bacillaceae) chitinase against Caenorhabditis elegans (Rhabditida: Rhabditidae). J. Econ. Entomol. 107, 551558. doi: 10.1603/ec13201

Zhong, W., Ding, S., and Guo, H. (2015). The chitinase C gene PsChiC from Pseudomonas sp. and its synergistic effects on larvicidal activity. Genet. Mol. Biol. 38, 366-372. doi: 10.1590/S1415-475738320140320

Zhong, W. F., Jiang, L. H., Yan, W. Z., Cai, P. Z., Zhang, Z. X., and Pei, Y. (2003). Cloning and sequencing of chitinase gene from Bacillus thuringiensis subsp israelensis. Yi Chuan Xue Bao 30, 364-369.

Conflict of Interest: The authors declare that the research was conducted in the absence of any commercial or financial relationships that could be construed as a potential conflict of interest.

Copyright (c) 2020 Martínez-Zavala, Barboza-Pérez, Hernández-Guzmán, Bideshi and Barboza-Corona. This is an open-access article distributed under the terms of the Creative Commons Attribution License (CC BY). The use, distribution or reproduction in other forums is permitted, provided the original author(s) and the copyright owner(s) are credited and that the original publication in this journal is cited, in accordance with accepted academic practice. No use, distribution or reproduction is permitted which does not comply with these terms. 